\title{
Semiaromatic Polyamides with Re-entrant Chain Folding Templated by “U-Turn” Repeat Units
}

\section{Supporting Information}

Julien Cretenoud, ${ }^{1}$ Michael Giffin, ${ }^{1}$ Bilal Özen, ${ }^{1}$ Farzaneh Fadaei Tirani, ${ }^{2}$

Rosario Scopelliti, ${ }^{2}$ Christopher J. G. Plummer, ${ }^{1}$ Holger Frauenrath ${ }^{1, *}$

${ }^{1}$ Ecole Polytechnique Fédérale de Lausanne (EPFL)
Institute of Materials
Laboratory of Macromolecular and Organic Materials

EPFL-STI-IMX-LMOM

MXG 037, Station 12

1015 Lausanne, Switzerland

holger.frauenrath@epfl.ch

${ }^{2}$ Ecole Polytechnique Fédérale de Lausanne (EPFL) Institute of Chemical Science and Engineering 


\section{Experimental}

\section{Materials and Instrumentation}

Materials. All materials and solvents for reactions were purchased from commercial suppliers and used without further purification. Chromatography solvents were purchased as reagent grades and distilled once prior to use. The progress of reactions was monitored by thin-layer chromatography (TLC) on Merck TLC plates (Silica gel $60 \mathrm{~F}_{254}$ ) using eluents of various polarities. UV light (254 nm) was used for detection of compounds on the TLC plates. Commercial polyamides poly(hexamethylene sebacoamide) (PA610, $\mathrm{Mn}=16,200 \mathrm{~g} / \mathrm{mol}, \mathrm{Mw}=28,800 \mathrm{~g} / \mathrm{mol}$ ), and poly(hexamethylene terephthalamide-coisophthalamide) (PA6TI, Mn = 11,700 g/mol, $\mathrm{Mw}=23,500 \mathrm{~g} / \mathrm{mol}$ ) were donated by EMS Chemie.

Mass Spectrometry. High-resolution mass spectrometry was carried out using either a Waters Q-ToF Ultima for ESI or a Waters QTOF Xevo G2-S for APCI/APPI. The MALDI-TOF mass spectra of the polyamides were acquired in reflectron mode, using an Axima-CFR Plus (Shimadzu Biotech) mass spectrometer, equipped with a nitrogen laser $(\lambda=337 \mathrm{~nm}$, pulse width $=3 \mathrm{~ns})$, operated in positive ion mode. The accelerating voltage was $20 \mathrm{kV}$ and the laser irradiance was maintained close to the instrument threshold. The specimens were prepared by mixing an appropriate volume of a solution of the polyamide ( $c=3 \mathrm{mg} / \mathrm{mL}$ in HFIP) with a matrix solution of $\alpha$-cyano-4-hydroxycinnamic acid $(c=10 \mathrm{mg} / \mathrm{mL}$ in THF) at volume ratios of $1: 1$ and $1: 10 \mathrm{v} / \mathrm{v}$. An aliquot of $1 \mu \mathrm{L}$ of each analyte/matrix mixture was then placed onto the MALDI sample holder and allowed to dry slowly in air.

Gel Permeation Chromatography (GPC). The number and weight average molecular weights, $M_{\mathrm{n}}$ and $M_{\mathrm{w}}$, and the dispersity indices, $\oslash$, of the polyamides and polyamide blends were determined using a 1260 Infinity GPC/SEC system (Agilent) with a refractive index detector and a column length of $650 \mathrm{~mm}$ (PSS PFG). 1,1,1,3,3,3-hexafluoropropane-2-ol (HFIP) was used as the eluent at a flow rate of $1 \mathrm{~mL} / \mathrm{min}$ and temperature of $35^{\circ} \mathrm{C}$. Eight poly(methyl methacrylate) (PMMA) standards with molar masses between 2'000 and $100^{\prime} 000 \mathrm{~g} / \mathrm{mol}$ and $Ð \leq 1.1$ were used for calibration. The polyamides, polyamide blends, and PMMA standards were all dissolved in neat HFIP $(c=3 \mathrm{mg} / \mathrm{mL})$.

Differential Scanning Calorimetry (DSC). DSC heating and cooling scans (TA Instruments Q100) were performed in nitrogen $(50 \mathrm{~mL} / \mathrm{min})$ using specimens of about $5 \mathrm{mg}$ and a scanning rate of $10^{\circ} \mathrm{C} / \mathrm{min} . T_{\mathrm{g}}$ 
was defined as the half-height of the heat capacity step associated with the glass transition during the second heating scans; $T_{\mathrm{m}}$ was taken to be the temperature corresponding to the maximum in the melting endotherm during the second heating scans; and $T_{\mathrm{c}}$ was taken to be the minimum in the crystallization exotherm observed during the cooling scans.

Thermogravimetric Analysis (TGA). TGA measurements were conducted on a Perkin Elmer TGA 4000. Samples (5-10 mg) were dried in high vacuum at $80^{\circ} \mathrm{C}$ for $24 \mathrm{~h}$, annealed in the TGA chamber at $110^{\circ} \mathrm{C}$ for $2 \mathrm{~min}$ and then heated from $30^{\circ} \mathrm{C}$ to $950^{\circ} \mathrm{C}$ at a scanning rate of $10^{\circ} \mathrm{C} / \mathrm{min}$ in nitrogen $(20 \mathrm{~mL} / \mathrm{min})$.

Wide-Angle X-ray Scattering and Modeling. Wide-angle X-ray scattering (WAXS) measurements were carried out with a PANalytical X'Pert Pro MPD diffractometer $(\mathrm{CuK} \alpha, \lambda=1.54 \AA$ ) in Bragg-Brentano geometry. The X-ray tube was operated at $45 \mathrm{kV}$ and $40 \mathrm{~mA}$. $2 \theta$ was scanned from 5 to $30^{\circ}$ using a fixed divergence slit of $0.25^{\circ}$, a step size of $0.0167^{\circ}$ and a time per step of $120.015 \mathrm{~s}$. Trial crystal structures for the acridine-based polyamides PAxAcr were generated ad hoc using the BIOVIA Materials Studio graphics user interface. Their geometry was then optimized with respect to all structural degrees of freedom subject to periodic boundary conditions, using classical force field-based energy minimization with the generic Dreiding force field ${ }^{1}$ and the method of steepest descents with charge equilibration. Wide-angle X-ray diffraction patterns were simulated using the BIOVIA Reflex software package.

$1 D$ and $2 D$ NMR Spectroscopy. ${ }^{1} \mathrm{H}$ and ${ }^{13} \mathrm{C}$ NMR spectroscopy was carried out at $298 \mathrm{~K}$ using a Bruker Avance III 400 spectrometer at frequencies of $400 \mathrm{MHz}$ and $100 \mathrm{MHz}$ respectively. The spectra were calibrated to the residual solvent peaks of DMSO- $d^{6}\left(2.50 \mathrm{ppm}{ }^{1} \mathrm{H}\right.$ NMR; $\left.39.52 \mathrm{ppm}{ }^{13} \mathrm{C} \mathrm{NMR}\right), \mathrm{CD}_{2} \mathrm{Cl}_{2}$ (5.32 ppm ${ }^{1} \mathrm{H}$ NMR; 53.84 ppm ${ }^{13} \mathrm{C}$ NMR) or $\mathrm{CDCl}_{3}\left(7.26 \mathrm{ppm}{ }^{1} \mathrm{H}\right.$ NMR; $77.16 \mathrm{ppm}{ }^{13} \mathrm{C}$ NMR). Concentration-dependent ${ }^{1} \mathrm{H}$ NMR spectroscopy of model compounds Acr-Hex and Ant-Pr (1-50 mM in $\mathrm{CD}_{2} \mathrm{Cl}_{2}$ ) was carried out at $298 \mathrm{~K}$ on the same instrument. Temperature-dependent ${ }^{1} \mathrm{H}-\mathrm{NMR}$ spectroscopy of model compounds Acr-Hex and Ant-Pr (1 mM in $\mathrm{CD}_{2} \mathrm{Cl}_{2}, 298-218 \mathrm{~K}$ ) was carried out using a Bruker Avance NEO 400 spectrometer equipped with a liquid Nitrogen cooling system at a frequency of $400 \mathrm{MHz}$. The ${ }^{1} \mathrm{H}$ NMR spectra of the polyamides were recorded at $298 \mathrm{~K}$ in $\mathrm{CDCl}_{3}$ containing 10 vol\% of 1,1,1,3,3,3-hexafluoropropan-2-ol- $d^{2}$ (HFIP- $\left.d_{2}\right)$ and calibrated with the residual solvent peaks of $\mathrm{CDCl}_{3}\left(7.26 \mathrm{ppm}{ }^{1} \mathrm{H} \mathrm{NMR}\right)$. 
Infrared Spectroscopy. Solid-state infrared (IR) spectra were recorded with a JASCO FT/IR 6300 spectrometer equipped with an ATR crystal. Solution-phase IR spectra were recorded on the same instrument using a cell mounted with two $\mathrm{KBr}$ windows. Second derivatives were calculated using the Savitzky-Golay algorithm (second order polynomial, 21 points).

Optical Spectroscopy. Solution-phase UV-vis spectra in acetonitrile (MeCN) or 1,1,1,3,3,3hexafluoropropane-2-ol (HFIP) using Hellma quartz cuvettes (1 cm path length) were recorded with a Jasco V-670 spectrometer. An excitation wavelength of $380 \mathrm{~nm}$ was chosen for photobleaching experiments on the polyamides, and absorption spectra of HFIP solutions (20 $\mu \mathrm{M})$ were recorded at different times over 3-4 h. Thin films were investigated using the same instrument. Thin films of model compounds and polyamides were prepared by spin-coating $100 \mu \mathrm{L}$ of a stock solution $(5 \mathrm{mg} / \mathrm{mL}$ in HFIP) onto a quartz substrate (5000 rpm, $1 \mathrm{~min}$ ). Solution-phase fluorescence emission spectra of the acridine and anthracene derivatives were recorded on a Jasco FP-6500 spectrofluorometer in MeCN or HFIP using Hellma quartz cuvettes $\left(1 \times 1 \mathrm{~cm}^{2}\right)$ with excitation wavelengths of 350 and $365 \mathrm{~nm}$ respectively. For solid-state fluorescence spectra, films of comprising solid particles of the compounds dispersed in a PMMA matrix were prepared by from dispersions that had been obtained from placing $5 \mathrm{mg}$ of the specimen in $5.2 \mathrm{~g}$ of a $17 \% \mathrm{w} / \mathrm{v}$ solution of PMMA in toluene under vigorous magnetic stirring. These dispersions were cast onto transparent polyester substrates (Byko-Charts, BYK Gardner, USA) using a doctor blade. The films were left to dry in air for 90-120 min and were further dried in high vacuum for $2 \mathrm{~d}$ after detachment from the substrate. The emission spectra of such films with a thickness of about $600 \mu \mathrm{m}$ were recorded with a Horiba Jobin Yvon FluoroMax-3.

X-ray Structure Analysis. The Bragg intensities of compounds Acr-Hex and Ant-Pr were measured at low temperature [100(2) K] using $\mathrm{Cu} K \alpha$ radiation with a Rigaku SuperNova dual system equipped with an Atlas CCD detector. The data sets were reduced and corrected for absorption with CrysAlisPro. ${ }^{2}$ Solution and refinement of the crystal structures were performed using SHELXS, ${ }^{3}$ SHELXT, ${ }^{4}$ and SHELXL-2017 (release 1). 5 The structures were refined using full-matrix least-squares based on $F^{2}$ with all non-hydrogen atoms defined anisotropically. The hydrogen atoms in compounds Acr-Hex and AntPr were located from the difference map and their positions refined freely. 
Computations. The structure of acridine Acr-Pr was optimized with the $\omega$ B97X-D ${ }^{6}$ density functional, combined with the def2-SVP basis set.7 The structural relaxation has been performed with implicit solvation (SMD model, ${ }^{8}$ solvent: dichloromethane). Harmonic thermochemical corrections were computed by a Hessian computation on the fully relaxed structure.

Dynamic Mechanical Analysis and Nanoindentation. Specimens of approximately $0.5 \mathrm{~g}$ were pressed for $10 \mathrm{~min}$ at $40 \mathrm{~N} / \mathrm{m}$ at $10^{\circ} \mathrm{C}$ below the melting point determined by DSC using a Lauffer Pressen UVL 5.0 laboratory press. Shear modulus measurements were performed on a Mettler-Toledo DMA/STDA861e, at room temperature of $27^{\circ} \mathrm{C}$. A frequency sweep was performed from $10 \mathrm{~Hz}$ to $0.1 \mathrm{~Hz}$ on a logarithmic scale, with 5 steps per decade, a force amplitude of $0.1 \mathrm{~N}$, and a displacement amplitude of $10 \mu \mathrm{m}$. Samples measured were between 300 and $500 \mu \mathrm{m}$ thick, with a geometry factor between $20 \mathrm{~m}^{-1}$ and $40 \mathrm{~m}^{-1}$. Nanoindentation experiments were carried out using an NHT2 Nanoindentation Tester from Anton Paar equipped with a Berkovich diamond indenter $(\alpha=65.3 \pm 0.3)$ on hot-pressed $300 \mu \mathrm{m}$ thick films. Loading and unloading rates were set to $100 \mathrm{mN} / \mathrm{min}$ with a pause of $30 \mathrm{~s}$, and the maximum load was set to $10 \mathrm{mN}$. From each specimen, 2-3 films were made and a minimum of 25 indents were performed on two different areas. The hardness $\left(H_{\mathrm{IT}}\right)$ and elastic modulus $\left(E_{\mathrm{IT}}\right)$ were determined from the unloading part of the measurement using Oliver and Pharr's analysis method, assumiong a Poisson's ratio of 0.4 .

\section{Synthetic Procedures}

4,5-Di(bromomethyl)acridine 1 . The synthesis of compound 1 was carried out according to a modified literature procedure, ${ }^{9}$ and the crude product $(50 \%$ yield $)$ was purified by column chromatography (dry loading, DCM/pentane 1:3, $\mathrm{R}_{\mathrm{f}}$ : 0.50 ) to give pure 4,5-di(bromomethyl)acridine 1 as a yellow solid. ${ }^{1} \mathrm{H}$ NMR (400 MHz, $\left.\mathrm{CDCl}_{3}\right): \delta=8.79(\mathrm{~s}, 2 \mathrm{H}), 8.00(\mathrm{~d}, J=8.5 \mathrm{~Hz}, 2 \mathrm{H}), 7.94(\mathrm{~d}, J=6.6 \mathrm{~Hz}$, 2H), $7.52(\mathrm{~m}, 2 \mathrm{H}), 4.53(\mathrm{~s}, 4 \mathrm{H}) \mathrm{ppm} .{ }^{13} \mathrm{C} \mathrm{NMR}\left(101 \mathrm{MHz}, \mathrm{CDCl}_{3}\right): \delta=145.92,136.65,136.62,131.25$, 129.16, 126.96, 125.98, 30.29 ppm. HRMS (ESI): calcd for $\mathrm{C}_{15} \mathrm{H}_{12} \mathrm{Br}_{2} \mathrm{~N}([\mathrm{M}+\mathrm{H}]+)$ : 363.9336 ; found: 363.9333. 
4,5-Di(cyanomethyl)acridine 2. 4,5-Di(bromomethyl)acridine 1 (4.03 g, $0.011 \mathrm{~mol}$ ) was suspended in DMF (200 mL), and NaCN (1.09 g, $0.022 \mathrm{~mol}, 2.01$ equiv.) was added in portions over $10 \mathrm{~min}$. NaCN should be handled with extreme caution as it can produce highly toxic hydrogen cyanide upon contact with acids, and $\mathrm{NaCN}$ can readily be absorbed into the skin in polar solvents. The mixture was stirred at room temperature for $2 \mathrm{~h}$, during which it turned into a clear solution. The volume of DMF was reduced to about $30 \mathrm{~mL}$ under reduced pressure and at controlled temperature $\left(<50^{\circ} \mathrm{C}\right)$ to avoid degradation of the product. The resulting slurry was then diluted with water $(250 \mathrm{~mL})$, and the precipitate was filtered off and washed with additional water. After drying in vacuum, 4,5-di(cyanomethyl)acridine 2 was obtained as a beige powder and used without further purification $(2.70 \mathrm{~g}, 95 \%$ yield $) .{ }^{1} \mathrm{H}$ NMR (400 $\left.\mathrm{MHz}, \mathrm{CDCl}_{3}\right): \delta=8.85(\mathrm{~s}, 1 \mathrm{H}), 8.05(\mathrm{~d}, J=8.5 \mathrm{~Hz}, 2 \mathrm{H}), 7.94(\mathrm{~d}, J=6.8 \mathrm{~Hz}, 2 \mathrm{H}), 7.63-7.54(\mathrm{~m}, 2 \mathrm{H}), 4.52(\mathrm{~s}$, 4H) ppm. ${ }^{13} \mathrm{C}$ NMR $\left(101 \mathrm{MHz}, \mathrm{CDCl}_{3}\right): \delta=145.82,137.11,130.12,129.44,128.85,126.74,126.00,118.62$, 20.91 ppm. HRMS (ESI): calcd for $\mathrm{C}_{17} \mathrm{H}_{12} \mathrm{~N}_{3}([\mathrm{M}+\mathrm{H}]+)$ ): 258.1031; found: 258.1035. Rf: 0.36 (DCM).

4,5-Di(carboxymethyl)acridinium hydrochloride 3. 4,5-Di(cyanomethyl)acridine 2 (6.24 g, 24.3 mmol) was saponified by heating a solution in concentrated $\mathrm{HCl}(35 \%, 400 \mathrm{~mL})$ to reflux overnight. After cooling the solution in an ice bath, it was diluted with cold water $(700 \mathrm{~mL})$, and $\mathrm{NaOH}$ pellets were carefully added to increase the $\mathrm{pH}$ to $13-14$. The basic solution was then transferred to an extraction funnel and washed with DCM $(2 \times 300 \mathrm{~mL})$. Acidification of the aqueous phase with concentrated $\mathrm{HCl}$ caused the product to precipitate as an orange-brown powder that was filtered off and washed several times with water to remove acid residues. The resulting 4,5-Di(carboxymethyl)acridinium hydrochloride 3 (5.95 g, 74\% yield) was used for ester or amide coupling reactions without further purification. ${ }^{1} \mathrm{H}$ NMR (400 MHz, DMSO- $\left.d_{6}\right): \delta=12.19(\mathrm{~s}, 2 \mathrm{H}), 9.11(\mathrm{~s}, 1 \mathrm{H}), 8.10(\mathrm{~d}, J=8.5 \mathrm{~Hz}, 2 \mathrm{H}), 7.77$ $(\mathrm{d}, J=6.8 \mathrm{~Hz}, 2 \mathrm{H}), 7.58(\mathrm{t}, J=7.6 \mathrm{~Hz}, 2 \mathrm{H}), 4.28(\mathrm{~s}, 4 \mathrm{H}) \mathrm{ppm} .{ }^{13} \mathrm{C}$ NMR $\left(101 \mathrm{MHz}, \mathrm{DMSO}-d^{6}\right): \delta=173.05$, 146.22, 136.60, 134.10, 130.76, 127.38, 125.98, 125.65, 36.70 ppm. HRMS (APCI): calcd for $\mathrm{C}_{17} \mathrm{H}_{14} \mathrm{NO}_{4}$ ([M+H]+): 296.0917; found: 296.0938.

4,5-Di(2-(N-succinimidyl)oxy-2-oxoethyl)acridine 4. The crude 4,5-Di(carboxymethyl)acridinium hydrochloride 3 (3.38 g, $10.19 \mathrm{mmol}$ ) was suspended in anhydrous DMF in an argon atmosphere. $N$ hydroxysuccinimide (NHS) (2.81 g, $24.45 \quad$ mmol, 2.4 equiv.), 1 -ethyl-3-(3- $N, N$ - 
dimethylaminopropyl)carbodiimide (EDCI) $\quad(7.81 \mathrm{~g}, 40.76 \mathrm{mmol}, 4$ equiv.) and $\quad \mathrm{N}, \mathrm{N}$ diisopropylethylamine (DIPEA) (8.9 mL, $50.95 \mathrm{mmol}, 5$ equiv.) were added successively to the suspension which subsequently turned into a clear solution. The solution was stirred for $2.5 \mathrm{~h}$, during which the reaction went to completion as confirmed by TLC. The volume of the solution was reduced to about $20 \mathrm{~mL}$ under reduced pressure $\left(55^{\circ} \mathrm{C}\right)$, and water $(300 \mathrm{~mL})$ was added to the resulting slurry. The precipitate was filtered off, washed with water, and dried in vacuum. The crude product (4.5 g) was purified by column chromatography (silica gel, DCM/MeOH 98:2) to give pure 4,5-di(2- $(N$ succinimidyl)oxy-2-oxoethyl)acridine 4 as a bright yellow powder (2.30 g, 46\% yield). ${ }^{1} \mathrm{H}$ NMR (400 $\left.\mathrm{MHz}, \mathrm{CDCl}_{3}\right): \delta=8.77(\mathrm{~s}, 1 \mathrm{H}), 7.97(\mathrm{~d}, J=8.4 \mathrm{~Hz}, 2 \mathrm{H}), 7.80(\mathrm{~d}, J=6.6 \mathrm{~Hz}, 2 \mathrm{H}), 7.52(\mathrm{dd}, J=8.4,6.9 \mathrm{~Hz}, 2 \mathrm{H})$, $4.80(\mathrm{~s}, 4 \mathrm{H}), 2.77(\mathrm{~s}, 8 \mathrm{H}) \mathrm{ppm} .{ }^{13} \mathrm{C}$ NMR (101 MHz, $\left.\mathrm{CDCl}_{3}\right): \delta=169.34,168.03,146.70,136.65,131.95$, 131.29, 128.39, 126.77, 125.79, 34.71, 25.73 ppm. HRMS (ESI): calcd for $\mathrm{C}_{25} \mathrm{H}_{20} \mathrm{~N}_{3} \mathrm{O}_{8}\left([\mathrm{M}+\mathrm{H}]^{+}\right)$: 490.1250; found: 490.1256. $\mathrm{R}_{\mathrm{f}}: 0.44$ (DCM/MeOH 98:2).

\section{4,5-Di(2-propylamino-2-oxoethyl)acridine (Acr-Pr).}

4,5-Di(carboxymethyl)acridinium hydrochloride 3 (0.94 g, $2.83 \mathrm{mmol})$ was suspended in $10 \mathrm{~mL}$ DMF, and 1-ethyl-3-(3dimethylaminopropyl)carbodiimide (1.19 g, $6.23 \mathrm{mmol}, 2.2$ equiv.) and 1-hydroxybenzotriazole hydrate (0.95 g, $6.23 \mathrm{mmol}, 2.2$ equiv.) were added. The mixture was stirred at room temperature for 15-20 min. $\mathrm{N}, \mathrm{N}$-diisopropylethylamine $(2.1 \mathrm{~mL}, 11.9 \mathrm{mmol}, 4.2$ equiv. $)$ and 1 -propylamine $(0.51 \mathrm{~mL}$, $6.23 \mathrm{mmol}, 2.2$ equiv.) were then successively added, and the resulting solution was stirred at room temperature overnight. It was then poured into water $(150 \mathrm{~mL})$, and the resulting precipitate was filtered off, washed with water, and dried in vacuum. The crude product was purified by column chromatography (silica gel, DCM/MeOH 15:1, 53\% yield) and subsequently recrystallized by slow diffusion of $\mathrm{Et}_{2} \mathrm{O}$ vapors into a DCM solution containing the product to obtain single crystals of 4,5-di(2propylamino-2-oxoethyl)acridine Acr-Pr suitable for X-ray analysis. ${ }^{1} \mathrm{H}$ NMR (400 MHz, DMSO- $\left.d_{6}\right): \delta$ $9.08(\mathrm{~s}, 1 \mathrm{H}), 8.07$ (d, $J=8.4 \mathrm{~Hz}, 2 \mathrm{H}), 8.03$ (t, $J=5.2 \mathrm{~Hz}, 2 \mathrm{H}), 7.75(\mathrm{~d}, J=6.7 \mathrm{~Hz}, 2 \mathrm{H}), 7.62-7.53(\mathrm{~m}, 2 \mathrm{H})$, $4.15(\mathrm{~s}, 4 \mathrm{H}), 3.03(\mathrm{q}, J=6.6 \mathrm{~Hz}, 4 \mathrm{H}), 1.38(\mathrm{~h}, J=7.2 \mathrm{~Hz}, 4 \mathrm{H}), 0.73(\mathrm{t}, J=7.4 \mathrm{~Hz}, 6 \mathrm{H}) \mathrm{ppm} .{ }^{13} \mathrm{C} \mathrm{NMR}(101$ MHz, DMSO-d ${ }^{6}$ ): $\delta=170.70,146.24,136.64,135.09,130.57,127.14,126.00,125.70,40.54,39.07,22.35$, 11.26 ppm. $T_{\mathrm{m}}$ (DSC): $234^{\circ} \mathrm{C} \mathrm{R}_{\mathrm{f}}: 0.34$ (DCM/MeOH 15:1). HRMS (ESI): calcd for $\mathrm{C}_{23} \mathrm{H}_{28} \mathrm{~N}_{3} \mathrm{O}_{2}\left([\mathrm{M}+\mathrm{H}]^{+}\right)$: 378.2181; found: 378.2175 . 
hydrochloride 3 (1.00 g, $3.01 \mathrm{mmol}$ ) was suspended in DMF (10 mL), and 1-ethyl-3-(3dimethylaminopropyl)carbodiimide (1.27 g, $6.63 \mathrm{mmol}, 2.2$ equiv.) and 1-hydroxybenzotriazole hydrate (1.02 g, $6.63 \mathrm{mmol}, 2.2$ equiv.) were added. The mixture was stirred at room temperature for 15-20 min. $N, N$-diisopropylethylamine (2.2 mL, $12.7 \mathrm{mmol}$, 4.2 equiv.) and 1-hexylamine $(0.87 \mathrm{~mL}, 6.63$ mmol, 2.2 equiv.) were then successively added, and the resulting solution was stirred at room temperature overnight. It was poured into water $(150 \mathrm{~mL})$, and the resulting precipitate was filtered, washed with water, and dried in vacuum. The crude product was purified by column chromatography (silica gel, DCM/MeOH 14:1, 47\% yield), and subsequently recrystallized from hot MeOH to yield 4,5di(2-hexylamino-2-oxoethyl)acridine Acr-Hex as yellow needle-like crystals suitable for X-ray analysis. ${ }^{1} \mathrm{H}$ NMR (400 MHz, DMSO-d $): \delta=9.08(\mathrm{~s}, 1 \mathrm{H}), 8.07(\mathrm{~d}, J=8.4 \mathrm{~Hz}, 2 \mathrm{H}), 7.99(\mathrm{t}, J=5.2 \mathrm{~Hz}, 2 \mathrm{H}), 7.75(\mathrm{~d}, J=$ $6.7 \mathrm{~Hz}, 2 \mathrm{H}), 7.57(\mathrm{t}, J=7.6 \mathrm{~Hz}, 2 \mathrm{H}), 4.12(\mathrm{~s}, 4 \mathrm{H}), 3.05(\mathrm{q}, J=6.4 \mathrm{~Hz}, 4 \mathrm{H}), 1.39-1.28(\mathrm{~m}, 4 \mathrm{H}), 1.04(\mathrm{~s}, 12 \mathrm{H})$, $0.71(\mathrm{t}, J=6.1 \mathrm{~Hz}, 6 \mathrm{H})$ ppm. ${ }^{13} \mathrm{C}$ NMR $\left(101 \mathrm{MHz}, \mathrm{DMSO}-d_{6}\right): \delta=170.68,146.24,136.61,135.06,130.69$, 127.16, 126.04, 125.69, 39.31, 38.72, 30.92, 29.04, 25.96, 21.92, 13.76 ppm. HRMS (ESI): calcd for $\mathrm{C}_{29} \mathrm{H}_{40} \mathrm{~N}_{3} \mathrm{O}_{2}\left([\mathrm{M}+\mathrm{H}]^{+}\right):$462.3120; found: 462.3125. $T_{\mathrm{m}}(\mathrm{DSC}): 201^{\circ} \mathrm{C} . \mathrm{R}_{\mathrm{f}}: 0.47$ (DCM/MeOH 14:1).

1,8-Di(2-ethoxy-2-oxoethoxy)anthraquinone 5. 1,8-dihydroxyanthraquinone (13.98 g, $58.2 \mathrm{mmol})$ was suspended in acetone (500 mL). Ethylbromoacetate $\left(16.1 \mathrm{~mL}, 0.145 \mathrm{~mol}, 2.5\right.$ equiv.) and $\mathrm{K}_{2} \mathrm{CO}_{3}$ (32.2 g, 0.23 mol, 4 equiv.) were added under vigorous stirring. The resulting mixture was refluxed overnight $\left(63^{\circ} \mathrm{C}\right)$ and the progress of the reaction was monitored by TLC. After cooling to room temperature, the purple precipitate was removed by filtration. The acetone and unreacted ethylbromoacetate were then removed under reduced pressure, and the crude product was purified by recrystallization from hot EtOH to give 1,8-di(2-ethoxy-2-oxoethoxy)anthraquinone $\mathbf{5}$ as a bright yellow solid (11.0 g, 46\% yield). ${ }^{1} \mathrm{H}$ NMR (400 MHz, $\left.\mathrm{CD}_{2} \mathrm{Cl}_{2}\right): \delta=7.87(\mathrm{~d}, J=7.7 \mathrm{~Hz}, 2 \mathrm{H}), 7.64(\mathrm{t}, J=8.0 \mathrm{~Hz}, 2 \mathrm{H})$, $7.22(\mathrm{~d}, J=8.3 \mathrm{~Hz}, 2 \mathrm{H}), 4.83(\mathrm{~s}, 4 \mathrm{H}), 4.27(\mathrm{q}, J=7.1 \mathrm{~Hz}, 4 \mathrm{H}), 1.29(\mathrm{t}, J=7.1 \mathrm{~Hz}, 6 \mathrm{H}) \mathrm{ppm} .{ }^{13} \mathrm{C}$ NMR $(151$ $\left.\mathrm{MHz}, \mathrm{CD}_{2} \mathrm{Cl}_{2}\right) \delta=183.70,182.19,168.71,157.91,135.28,134.17,125.20,120.59,120.53,67.13,61.91$, 14.33 ppm. HRMS (ESI): calcd for $\mathrm{C}_{22} \mathrm{H}_{20} \mathrm{O}_{8} \mathrm{Na}\left([\mathrm{M}+\mathrm{Na}]^{+}\right)$: 435.1056; found: 435.1059 . $\mathrm{R}_{\mathrm{f}}: 0.37$ (petroleum ether/EtOAc 1:1). 
1,8-Di(carboxymethoxy)anthraquinone 6. 1,8-di(2-ethoxy-2-oxoethoxy)anthraquinone 5 was saponified according to a literature procedure.10 The crude 1,8-di(carboxymethoxy)anthraquinone 6 (93\% yield) was not isolated and used without further purification.

1,8-Di(carboxymethoxy)anthracene 7. 1,8-di(carboxymethoxy)anthraquinone 6 (8.75 g, 24.56 mmol) was suspended in aqueous $\mathrm{NH}_{4} \mathrm{OH}(25 \%, 500 \mathrm{~mL})$. Zinc powder (8.03 g, 0.122 mol, 5 equiv.) was added, and the mixture was stirred under reflux $\left(68^{\circ} \mathrm{C}\right)$ for $3 \mathrm{~h}$. The reaction mixture was then cooled, additional zinc powder (6.42 g, 4 equiv.) in aqueous $\mathrm{NH}_{4} \mathrm{OH}(25 \%, 50 \mathrm{~mL}$ ) was added, and reflux was continued overnight. The solution was then cooled in an ice bath before acidification to $\mathrm{pH} 1 \mathrm{with}$ concentrated aqueous $\mathrm{HCl}$ (37\%), which resulted in a beige precipitate that was too fine to be filtered. The aqueous phase was therefore extracted with EtOAc $(3 \times 350 \mathrm{~mL})$, and the combined organic phases were washed once with water $(400 \mathrm{~mL})$ and once with brine $(400 \mathrm{~mL})$, and dried over $\mathrm{MgSO}_{4}$. The solvent was evaporated under reduced pressure. After drying in vacuum, pure 1,8di(carboxymethoxy)anthracene 7 was obtained as a light brown powder (5.76 g, 73\% yield). ${ }^{1} \mathrm{H}$ NMR (400 MHz, DMSO- $\left.d_{6}\right): \delta=13.13(\mathrm{~s}, 2 \mathrm{H}), 9.22(\mathrm{~s}, 1 \mathrm{H}), 8.48(\mathrm{~s}, 1 \mathrm{H}), 7.65(\mathrm{~d}, J=8.6 \mathrm{~Hz}, 2 \mathrm{H}), 7.41(\mathrm{t}, J=8.0$ $\mathrm{Hz}, 2 \mathrm{H}), 6.81(\mathrm{~d}, J=7.5 \mathrm{~Hz}, 2 \mathrm{H}), 5.00(\mathrm{~s}, 4 \mathrm{H}) \mathrm{ppm} .{ }^{13} \mathrm{C}$ NMR (101 MHz, DMSO-d6): $\delta=170.07,153.54$, $132.44,125.91,125.24,123.63,120.47,115.19,103.20,64.80$ ppm. HRMS (ESI): calcd for $\mathrm{C}_{18} \mathrm{H}_{13} \mathrm{O}_{6}$ ([MH]-): 325.0712; found: 325.0715 .

1,8-Di(2-propylamino-2-oxoethoxy)anthracene (Ant-Pr). 1,8-Di(carboxymethoxy)anthracene 7 (2.01 g, $6.16 \mathrm{mmol})$ was suspended in DMF $(20 \mathrm{~mL})$, and 1-ethyl-3-(3dimethylaminopropyl)carbodiimide (2.60 g, $13.6 \mathrm{mmol}, 2.2$ equiv.) and 1-hydroxybenzotriazole hydrate $(2.07 \mathrm{~g}, 13.6 \mathrm{mmol}, 2.2$ equiv.) were added. The mixture was stirred at room temperature for 15-20 min. $N, N$-diisopropylethylamine (4.5 mL, $25.9 \mathrm{mmol}, 4.2$ equiv.) and 1-propylamine $(1.10 \mathrm{~mL}$, $13.6 \mathrm{mmol}, 2.2$ equiv.) were then successively added, and the resulting solution was stirred at room temperature overnight. It was then poured into water $(200 \mathrm{~mL})$, and the resulting precipitate was filtered, washed with water, and dried in vacuum. The crude product was purified by column chromatography (silica gel, DCM/MeOH 19:1, 56\% yield), followed by recrystallization by slow evaporation (16 h) a solution of 1,8-di(2-propylamino-2-oxoethoxy)anthracene Ant-Pr in DCM/MeOH 
$(10: 1,0.2 \mathrm{M})$ at room temperature. The resulting transparent needle-like crystals were suitable for Xray analysis. ${ }^{1} \mathrm{H}$ NMR (400 MHz, DMSO- $\left.d_{6}\right): \delta=9.28(\mathrm{~s}, 1 \mathrm{H}), 8.49(\mathrm{~s}, 1 \mathrm{H}), 8.24(\mathrm{t}, J=5.4 \mathrm{~Hz}, 2 \mathrm{H}), 7.66(\mathrm{~d}$, $J=8.5 \mathrm{~Hz}, 2 \mathrm{H}), 7.42(\mathrm{t}, J=8.0 \mathrm{~Hz}, 2 \mathrm{H}), 6.82(\mathrm{~d}, J=7.5 \mathrm{~Hz}, 2 \mathrm{H}), 4.78(\mathrm{~s}, 4 \mathrm{H}), 3.15(\mathrm{q}, J=6.6 \mathrm{~Hz}, 4 \mathrm{H}), 1.49$ $(\mathrm{h}, J=7.2 \mathrm{~Hz}, 4 \mathrm{H}), 0.86(\mathrm{t}, J=7.4 \mathrm{~Hz}, 6 \mathrm{H}) \mathrm{ppm} .{ }^{13} \mathrm{C}$ NMR $\left(101 \mathrm{MHz}, \mathrm{DMSO}-d^{6}\right): \delta=167.33,153.75,132.41$, 125.90, 125.19, 123.59, 120.62, 115.73, 103.61, 67.55, 40.16, 22.35, 11.30 ppm. HRMS (ESI): calcd for $\mathrm{C}_{24} \mathrm{H}_{29} \mathrm{~N}_{2} \mathrm{O}_{4}([\mathrm{M}+\mathrm{H}]+)$ ): 409.2127; found: 409.2129. $\mathrm{R}_{\mathrm{f}}: 0.46$ (DCM/MeOH 19:1).

General Procedure A for the Preparation of the Acridine-Based Polyamides. A thoroughly dried $10 \mathrm{~mL}$ Schlenk tube was purged with argon and charged with the corresponding aliphatic diamine (0.7$0.8 \mathrm{mmol}, \quad 1.00$ equiv.), 4,5-di(2-( $N$-succinimidyl)oxy-2-oxoethyl)acridine $4 \quad(1.00$ equiv.), and anhydrous DMSO (3.1-3.4 mL). The suspension was heated to $120^{\circ} \mathrm{C}$ under vigorous stirring, at which point it briefly converted to a clear solution. After $2 \mathrm{~h}$, the reaction mixture was cooled to $50-60^{\circ} \mathrm{C}$ and poured into cold water $(40 \mathrm{~mL})$. The resulting yellow precipitate was filtered off, washed with water and acetone, and dried in vacuum to yield the corresponding polyamide $\operatorname{PAxAcr}(x=6,8,10,12)$.

General Procedure B for the Preparation of Anthracene-Based Polyamides. A thoroughly dried $50 \mathrm{~mL}$ Schlenk tube was purged with argon and charged with the corresponding aliphatic diamine (2-3 mmol, 1.00 equiv.), 1,8-di(carboxymethoxy)anthracene 7 (1.00 equiv.), anhydrous $N$-methylpyrrolidone (6.4$9.7 \mathrm{~mL}$ ), anhydrous pyridine (1.6-2.4 mL), triphenylphosphite (1.0-1.6 mL, 2.01 equiv.), and anhydrous lithium chloride (0.41-0.62 g). The suspension was heated to $120^{\circ} \mathrm{C}$ under vigorous stirring, at which point it briefly turned into a clear solution. After $4 \mathrm{~h}$, the reaction mixture was cooled to $50-60^{\circ} \mathrm{C}$ and poured into $\mathrm{MeOH}(100 \mathrm{~mL})$. The resulting brown precipitate was filtered off, washed with hot $\mathrm{MeOH}$, extracted with refluxing $\mathrm{MeOH}$ for $24 \mathrm{~h}$, filtered off again, and dried in vacuum to yield the corresponding polyamide PAxAnt $(x=6,8,10,12)$.

PA6Acr. The polyamide PA6Acr was prepared following general procedure A from 4,5-di(2- $(N$ succinimidyl)oxy-2-oxoethyl)acridine $4(412 \mathrm{mg}, 0.84 \mathrm{mmol}$ ) and 1,6-diaminohexane (98 $\mathrm{mg}$, $0.84 \mathrm{mmol}$ ). The polyamide PA6Acr was obtained as a yellow powder in a yield of $73 \%$. ${ }^{1} \mathrm{H}$ NMR (400 MHz, CDCl $3 / \mathrm{HFIP}_{2} d_{2}$ 9:1): $\delta=9.74-8.54(\mathrm{~m}, 1 \mathrm{H}), 8.46-7.31(\mathrm{~m}, 6 \mathrm{H}), 4.33-3.83(\mathrm{~m}, 4 \mathrm{H}), 3.22-2.50$ $(\mathrm{m}, 4 \mathrm{H}), 1.72-0.34(\mathrm{~m}, 8 \mathrm{H})$. 
PA8Acr. The polyamide PA8Acr was prepared following general procedure A from 4,5-di(2- $(N$ succinimidyl)oxy-2-oxoethyl)acridine 4 (384 mg, $0.78 \mathrm{mmol}$ ) and 1,8-diaminooctane (113 $\mathrm{mg}$, $0.78 \mathrm{mmol}$ ). The polyamide PA8Acr was obtained as a yellow powder in a yield of $80 \%$. ${ }^{1} \mathrm{H} \mathrm{NMR}$ (400 MHz, CDCl 3 /HFIP- $d_{2}$ 9:1): $\delta=8.79(\mathrm{~s}, 1 \mathrm{H}), 8.33-7.37(\mathrm{~m}, 6 \mathrm{H}), 4.46-3.98(\mathrm{~m}, 4 \mathrm{H}), 3.32-2.96(\mathrm{~m}, 4 \mathrm{H})$, $1.62-0.38(\mathrm{~m}, 12 \mathrm{H})$.

PA10Acr. The polyamide PA10Acr was prepared following general procedure A from 4,5-di(2- $(N-$ succinimidyl)oxy-2-oxoethyl)acridine $4(340 \mathrm{mg}, 0.70 \mathrm{mmol})$ and 1,10-diaminodecane (120 $\mathrm{mg}$, $0.70 \mathrm{mmol}$ ). The polyamide PA10Acr was obtained as a yellow powder in a yield of $87 \%$. ${ }^{1} \mathrm{H}$ NMR (400 MHz, CDCl 3 HFIP- $d_{2}$ 9:1): $\delta=8.81(\mathrm{~s}, 1 \mathrm{H}), 8.44-7.33(\mathrm{~m}, 6 \mathrm{H}), 4.37-3.99(\mathrm{~m}, 4 \mathrm{H}), 3.30-2.98(\mathrm{~m}, 4 \mathrm{H})$, $1.70-0.56(\mathrm{~m}, 16 \mathrm{H})$.

PA12Acr. The polyamide PA12Acr was prepared following general procedure A from 4,5-di(2- $(N$ succinimidyl)oxy-2-oxoethyl)acridine 4 (342 mg, $0.70 \mathrm{mmol}$ ) and 1,12-diaminododecane (140 mg, $0.70 \mathrm{mmol}$ ). The polyamide PA12Acr was obtained as a yellow powder in a yield of 86\%. ${ }^{1} \mathrm{H} \mathrm{NMR}$ (400 MHz, CDCl 3 /HFIP- $d_{2}$ 9:1): $\delta=8.84(\mathrm{~s}, 1 \mathrm{H}), 8.30-7.42(\mathrm{~m}, 6 \mathrm{H}), 4.35-4.04(\mathrm{~m}, 4 \mathrm{H}), 3.23-2.91(\mathrm{~m}, 4 \mathrm{H})$, $1.64-0.59(\mathrm{~m}, 20 \mathrm{H})$.

PA6Ant. The polyamide PA6Ant was prepared following general procedure B 1,8di(carboxymethoxy)anthracene 7 (786 mg, $2.41 \mathrm{mmol}$ ) and 1,6-diaminohexane (280 mg, $2.41 \mathrm{mmol})$. The polyamide PA6Ant was obtained as a brown powder in a yield of $61 \%$. ${ }^{1} \mathrm{H} \mathrm{NMR}(400 \mathrm{MHz}$, $\mathrm{CDCl}_{3} / \mathrm{HFIP}_{2} d_{2}$ 9:1): $\delta=9.21-9.01(\mathrm{~m}, 1 \mathrm{H}), 8.42-8.24(\mathrm{~m}, 1 \mathrm{H}), 7.74-7.52(\mathrm{~m}, 2 \mathrm{H}), 7.46-7.27(\mathrm{~m}, 2 \mathrm{H})$, 6.73-6.55 (m, 2H), 4.84-4.59 (m, 4H), 3.38-2.95 (m, 4H), 1.65-0.99 (m, 8H).

PA8Ant. The polyamide PA8Ant was prepared following general procedure B from 1,8di(carboxymethoxy)anthracene 7 (666 mg, $2.04 \mathrm{mmol}$ ) and 1,8-diaminooctane (294 mg, $2.04 \mathrm{mmol}$ ). The polyamide PA8Ant was obtained as a brown powder in a yield of $62 \%$. ${ }^{1} \mathrm{H}$ NMR $(400 \mathrm{MHz}$, $\mathrm{CDCl}_{3} / \mathrm{HFIP}_{2} d_{2}$ 9:1): $\delta=9.24-9.01(\mathrm{~m}, 1 \mathrm{H}), 8.47-8.30(\mathrm{~m}, 1 \mathrm{H}), 7.78-7.57(\mathrm{~m}, 2 \mathrm{H}), 7.49-7.29(\mathrm{~m}, 2 \mathrm{H})$, 6.78-6.59 (m, 2H), 4.85-4.66 (m, 4H), 3.42-2.96 (m, 4H), 1.68-0.99 (m, 12H).

PA10Ant. The polyamide PA10Ant was prepared following general procedure B from 1,8di(carboxymethoxy)anthracene 7 (980 mg, $3.02 \mathrm{mmol}$ ) and 1,10-diaminodecane (520 mg, $3.02 \mathrm{mmol}$ ). 
The polyamide PA10Ant was obtained as a brown powder in a yield of $65 \%$. ${ }^{1} \mathrm{H} \mathrm{NMR}(400 \mathrm{MHz}$, $\mathrm{CDCl}_{3} / \mathrm{HFIP}-d_{2}$ 9:1): $\delta=9.12(\mathrm{~s}, 1 \mathrm{H}), 8.49-8.31(\mathrm{~m}, 1 \mathrm{H}), 7.79-7.59(\mathrm{~m}, 2 \mathrm{H}), 7.49-7.31(\mathrm{~m}, 2 \mathrm{H}), 6.79-6.62$ (m, 2H), $4.78(\mathrm{~s}, 4 \mathrm{H}), 3.43-2.97(\mathrm{~m}, 4 \mathrm{H}), 1.69-0.97(\mathrm{~m}, 16 \mathrm{H})$.

PA12Ant. The polyamide PA12Ant was prepared following general procedure B from 1,8di(carboxymethoxy)anthracene 7 (632 mg, $1.94 \mathrm{mmol}$ ) and 1,12-diaminododecane (388 mg, $1.94 \mathrm{mmol}$ ). The polyamide PA12Ant was obtained as a brown powder in a yield of $75 \%$. ${ }^{1} \mathrm{H}$ NMR (400 MHz, CDCl 3 HFIP- $d_{2}$ 9:1): $\delta=9.11(\mathrm{~s}, 1 \mathrm{H}), 8.50-8.30(\mathrm{~m}, 1 \mathrm{H}), 7.80-7.61(\mathrm{~m}, 2 \mathrm{H}), 7.46-7.31(\mathrm{~m}, 2 \mathrm{H})$, 6.78-6.61 (m, 2H), 4.97-4.64 (m, 4H), 3.43-2.98 (m, 4H), 1.72-0.94 (m, 20H). 


\section{Supplementary Schemes}

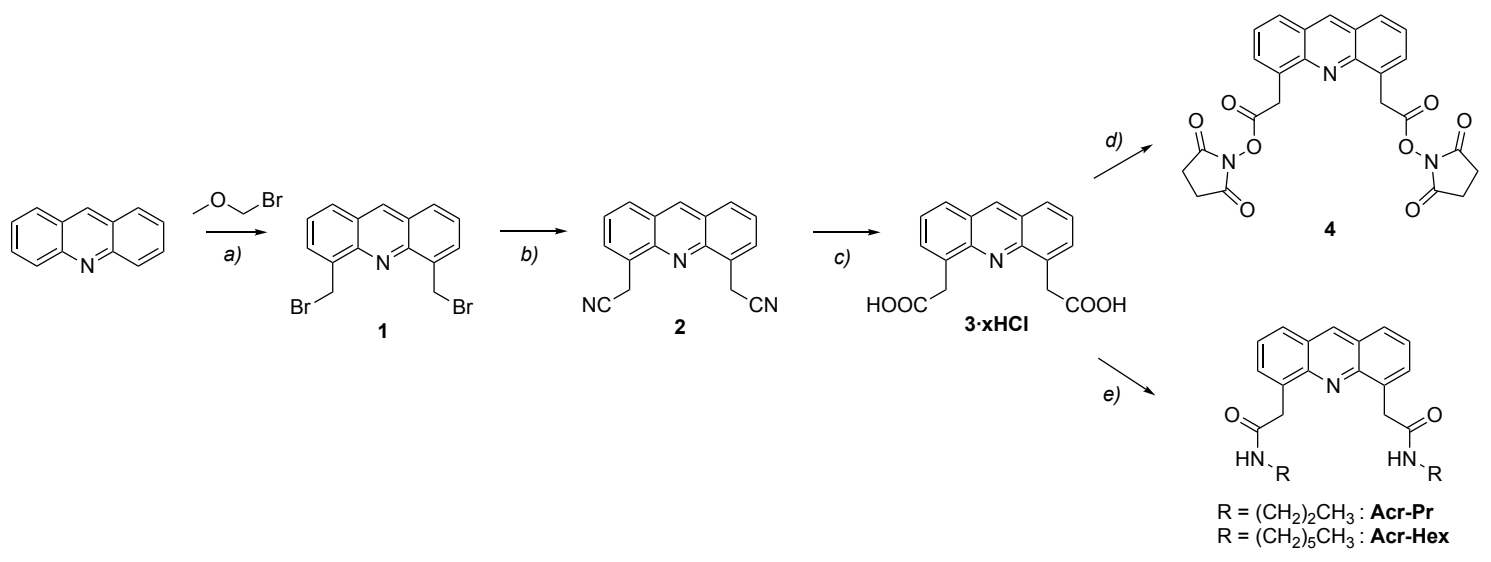

Supplementary Scheme S1. Synthesis of acridine-based active ester monomers for polycondensations and diamide model compounds. The synthesis of an acridine-based monomer started with the selective two-fold introduction of bromomethyl substituents at the 4,5-positions of acridine analogously to published procedures. ${ }^{9}$ The subsequent two-fold cyanation of di(bromomethyl)acridine $\mathbf{1}$ with sodium cyanide was then performed at room temperature in DMF. Care was taken to not raise the temperature above $40-50^{\circ} \mathrm{C}$ during the course of the reaction because the di(cyanomethyl)acridine 2 was found to degrade at higher temperatures. Because of the high reactivity of the acridine core towards reducing reagents, we opted for an acidic hydrolysis of the nitrile groups to obtain the di(carboxymethyl)acridinium hydrochloride 3 . The esterification of $\mathbf{3}$ with $\mathrm{N}$-hydroxysuccinimide yielded the acridine monomer $\mathbf{4}$. This four-step synthesis was subsequently scaled up to the multi-gram scale with a $16 \%$ overall yield, which was primarily limited by the moderate $50 \%$ yield of the initial selective 4,5-dibromomethylation. Moreover, amide coupling of the di(carboxymethyl)acridinium hydrochloride 3 with either 1-propylamine or 1-hexylamine using EDCI/HOBt as coupling promoters furnished the acridine di(propyl amide) Acr-Pr and the di(hexylamide) Acr-Hex, respectively, which are to serve as model compounds for studying the packing of the hydrogenbonded U-turn frameworks. Reagents and conditions: a) $\mathrm{H}_{2} \mathrm{SO}_{4}$ (conc.), $50^{\circ} \mathrm{C}, 16 \mathrm{~h}, 50 \%$; b) $\mathrm{NaCN}$, DMF, r.t., $2 \mathrm{~h}, 95 \%$; c) $\mathrm{HCl}$ (conc.), reflux, 16 h, 74\%. d) NHS (2 equiv.), EDCI, DIPEA, DMF, r.t., 2.5 h, 46\%; e) 1-propylamine or 1-hexylamine (2 equiv.), EDCI, HOBt, DIPEA, DMF, r.t., 16 h, 47-53\%. 
<smiles>O=C1c2cccc(O)c2C(=O)c2cccc(O)c21</smiles><smiles>CCOC(=O)CBr</smiles><smiles>CCOC(=O)COc1cccc2c1C(=O)c1c(OCC(=O)OCC)cccc1C2=O</smiles>
5<smiles>O=C(O)COc1cccc2c1C(=O)c1c(OCC(=O)O)cccc1C2=O</smiles>

c)

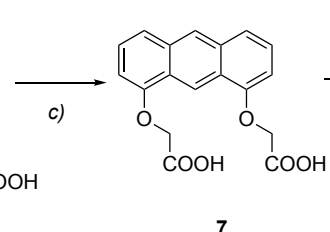

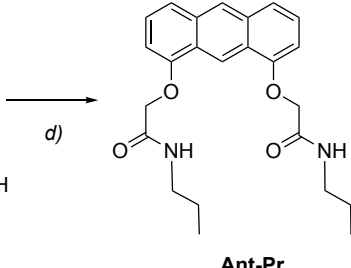

Ant-Pr

Supplementary Scheme S2. Synthesis of anthracene-based active ester monomers for polycondensations and diamide model compounds. The synthesis of an anthracene-based monomer started by the two-fold ether coupling of commercially available 1,8-dihydroxyanthraquinone to ethyl bromoacetate yielding the anthraquinone diester $\mathbf{5}$, followed by saponification to obtain the anthraquinone dicarboxylic acid 6, analogous to established procedures.10-12 Reduction of the anthraquinone using zinc powder in a refluxing aqueous $\mathrm{NH}_{4} \mathrm{OH}$ solution then furnished the corresponding anthracene dicarboxylic acid 7. Avoiding a large an excess of zinc in this last step turned out to be critical, as it resulted in over-reduction of the anthracene core. The anthracene dicarboxylic acid Ant-Pr was subsequently synthesized on a multi-gram scale from commercially available precursors with a $31 \%$ total yield over the three steps of the synthesis, limited mainly by the purification of compound 5 by recrystallization. We finally performed an EDCI/HOBt-promoted peptide coupling of $\mathbf{7}$ and 1propylamine to prepare the di(propylamide) Ant-Pr as a model compound for packing analysis. Reagents and conditions: a) $\mathrm{K}_{2} \mathrm{CO}_{3}$, acetone, reflux, $16 \mathrm{~h}, 46 \%$; b) LiOH, THF/water 4:1, reflux, $16 \mathrm{~h}, 93 \%$; c) Zn powder, aq. $\mathrm{NH}_{4} \mathrm{OH}(25 \%)$, reflux, 16 h, $73 \%$; d) 1-propylamine (2 equiv.), EDCI, HOBt, DIPEA, DMF, r.t., 16 h, 97\%. 


\section{Supplementary Figures}

a)

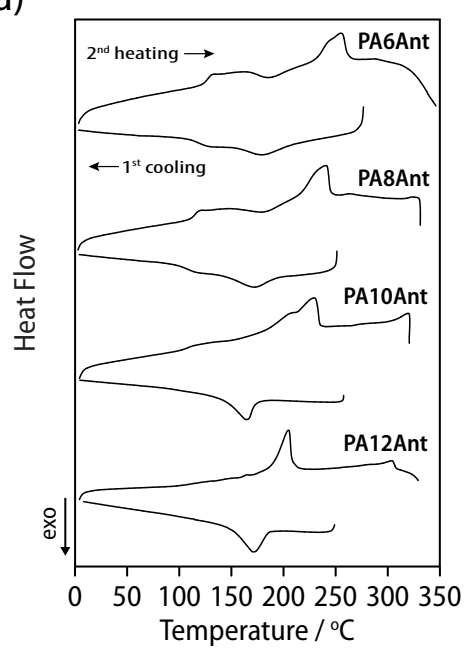

c)

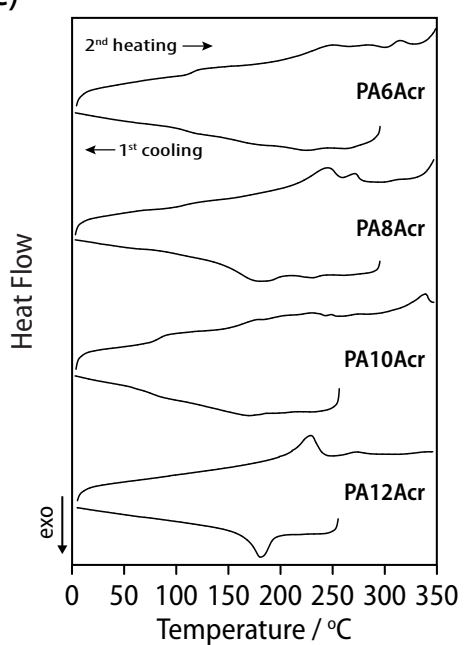

b)

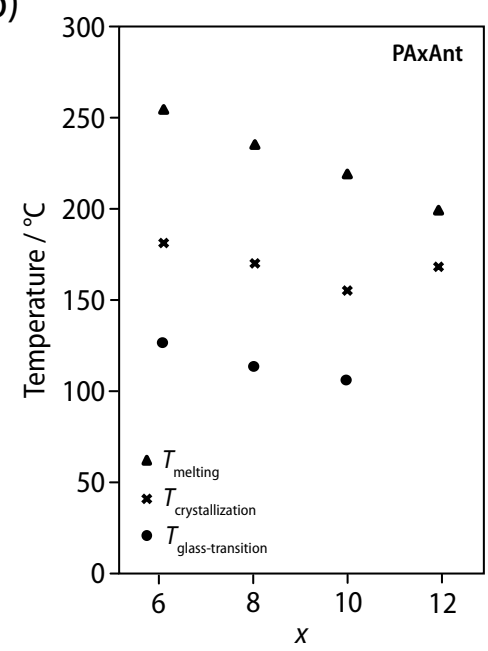

d)

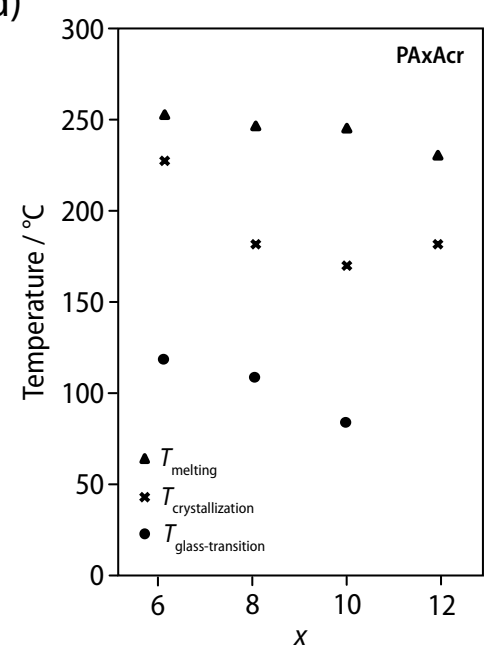

Supplementary Figure S1.

a) First cooling and second heating DSC scans of PAxAnt (10 K/min, in nitrogen). b) $T_{\mathrm{g}}$,

$T_{\mathrm{m}}$ and $T_{\mathrm{c}}$ in the polyamide series PAxAnt as a function of $\left.x . \quad c\right)$ First cooling and second heating DSC scans of PAxAcr (10 K/min, in nitrogen). d) $T_{\mathrm{g}}, T_{\mathrm{m}}$ and $T_{\mathrm{c}}$ in the polyamide series PAxAcr as a function of $x$. 
a)

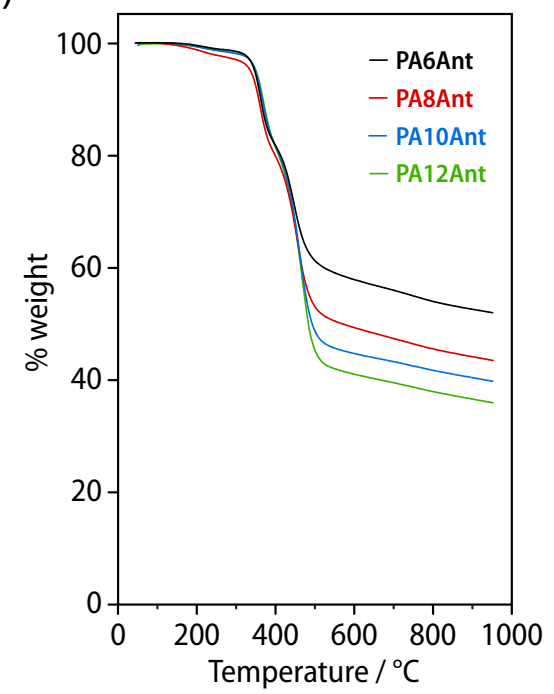

b)

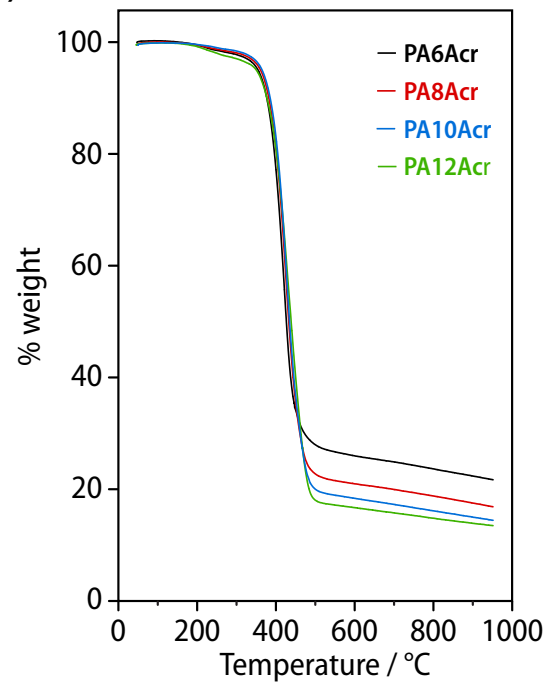

Supplementary Figure S2. Thermogravimetric analysis (TGA) data for a) the polyamides PAxAnt, and b) the polyamides PAxAcr. 
a)

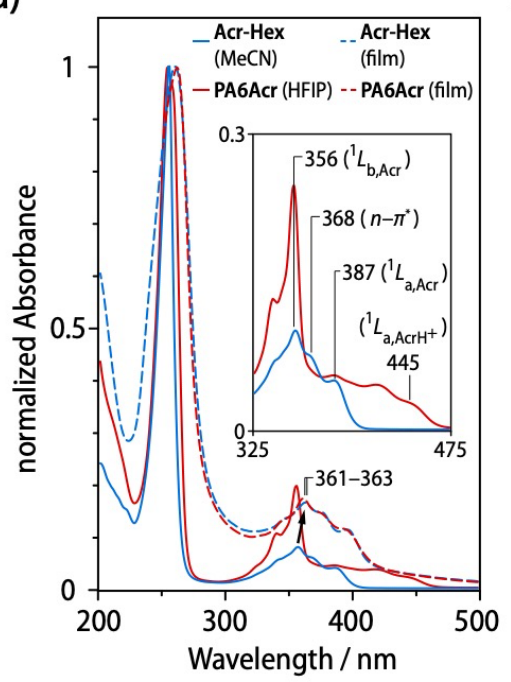

b)

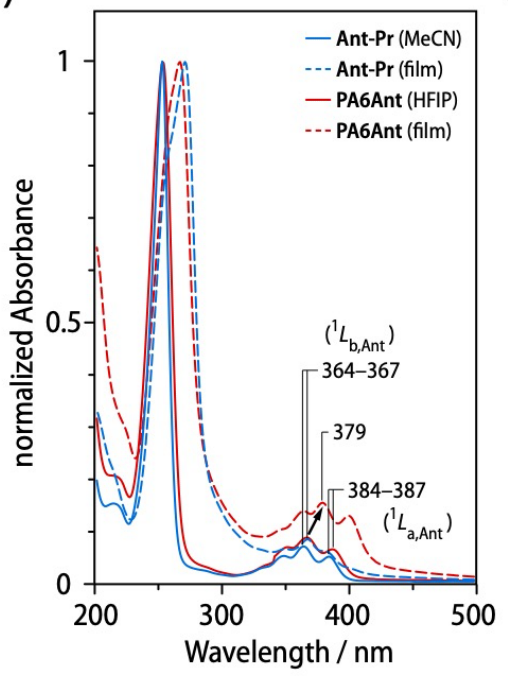

c)

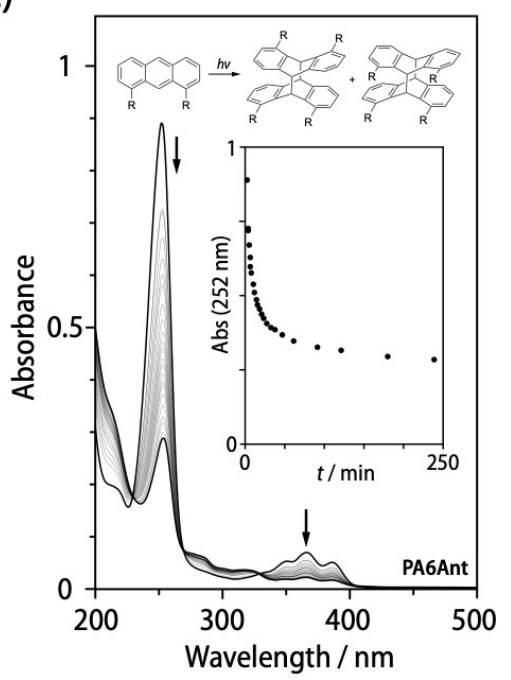

d)

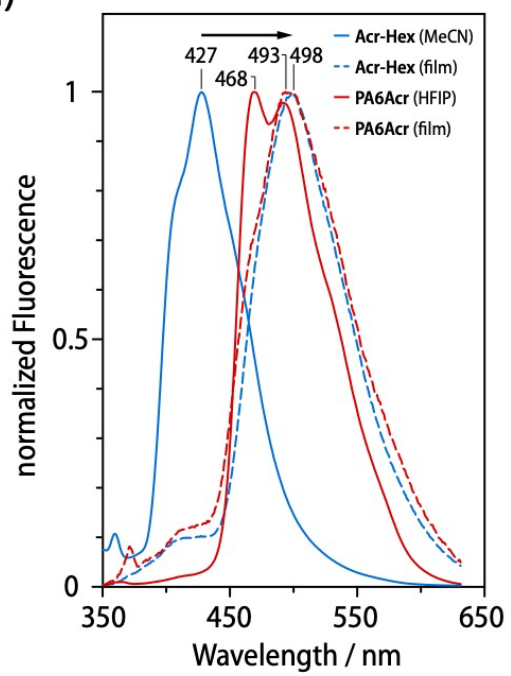

e)

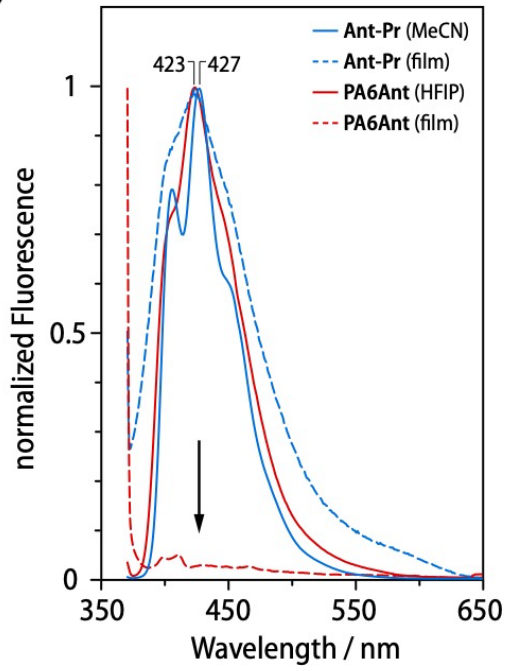

Supplementary Figure S3. Normalized absorption spectra of a) PA6Acr and b) PA6Ant with respect to the model compounds Acr-Hex and Ant-Pr in solution (solid lines) and films spin-coated onto quartz substrate (dotted lines). The insert in $a$ ) shows a zoom of the visible region of the solution spectra with all the characteristic electronic transitions of the acridine moiety (Acr). As the low solubility of the polyamides in organic solvents made it necessary to use HFIP as a cosolvent, the acridine-based polyamides became partially protonated. This is reflected by a broad shoulder centered at about $410 \mathrm{~nm}$ in the absorbance spectrum of PA6Acr, resulting from a shift in the first electronic transition $\left(\pi-\pi^{*}, 1{ }^{2}\right)$ from 356 to $445 \mathrm{~nm}$ (a).13-16 Thin films prepared from the acridine model compound Acr-Hex and PA6Acr both retained the electronic structure of the non-protonated model compounds in solution, with a weak solid-state red-shift (5-7 nm). The electronic states of the anthracene-based polymers were found to be similar to the acridine-based polymers, with the obvious absence of any $n-\pi^{*}$ transition. c) Photodimerization observed for PA6Ant at room temperature in an HFIP solution (20 $\mu \mathrm{M})$ upon excitation at $380 \mathrm{~nm}$. The insert shows the decay of the main absorption peak over time ( $\left.t_{1 / 2}=16 \mathrm{~min}\right)$. d,e) Emission spectra for PA6Acr and PA6Ant with respect to the model compounds Acr-Hex and Ant-Pr in solution (solid lines) and solid films (dashed lines, dispersions in a PMMA matrix), recorded at an excitation wavelength of 350 and $365 \mathrm{~nm}$ respectively. The intensity maximum in the fluorescence emission spectra of films of Acr-Hex and PA6Acr was red-shifted in both cases by about $70 \mathrm{~nm}$ as compared to the non-protonated model compound, which we attribute to the formation of excimers. PA6Ant and Ant-Pr showed similar fluorescence in solution, but PA6Ant exhibited fluorescence quenching in films, possibly due to photodimerization. ${ }^{17-20}$ 


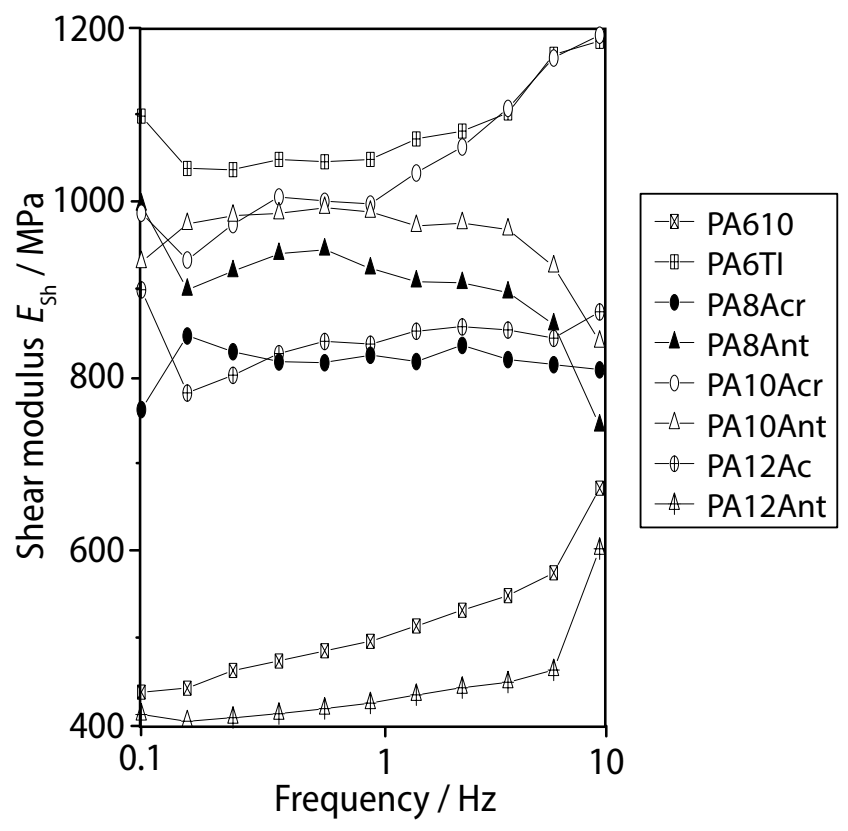

Supplementary Figure S4. Frequency-dependent dynamic mechanical analysis curves for PAxAcr (circles) and PAxAcr (triangles) as well as commercial polyamides (squares) PA6TI and PA610. 


\section{Supplementary Tables}

Supplementary Table S1. Crystallographic data for the compounds Acr-Pr, Acr-Hex and Ant-Pr.

\begin{tabular}{|c|c|c|c|}
\hline Compound & Acr-Pr & Acr-Hex & Ant-Pr \\
\hline Formula & $\mathrm{C}_{23} \mathrm{H}_{27} \mathrm{~N}_{3} \mathrm{O}_{2}$ & $\mathrm{C}_{29} \mathrm{H}_{39} \mathrm{~N}_{3} \mathrm{O}_{2}$ & $\mathrm{C}_{25} \mathrm{H}_{30} \mathrm{~N}_{2} \mathrm{O}_{4} \mathrm{Cl}_{2}$ \\
\hline$D_{\text {calc. }} / \mathrm{g} \mathrm{cm}^{-3}$ & 1.278 & 1.173 & 1.327 \\
\hline$\mu / \mathrm{mm}^{-1}$ & 0.655 & 0.575 & 2.642 \\
\hline Formula Weight & 377.47 & 461.63 & 493.41 \\
\hline Colour & colourless & colourless & clear pale green \\
\hline Shape & needle & needle & plate \\
\hline Size $/ \mathrm{mm}^{3}$ & $0.42 \times 0.11 \times 0.10$ & $0.87 \times 0.09 \times 0.03$ & $0.53 \times 0.41 \times 0.18$ \\
\hline$T / \mathrm{K}$ & $100.00(10)$ & $99.99(10)$ & $100.01(10)$ \\
\hline Crystal System & triclinic & triclinic & monoclinic \\
\hline Space Group & $P \overline{1}$ & $P \overline{1}$ & $P 2{ }_{1} / c$ \\
\hline$a / \AA ̊$ & $4.9081(5)$ & $4.8589(3)$ & $16.7948(3)$ \\
\hline$b / \AA ̊$ & $17.174(4)$ & $16.4620(11)$ & $15.6952(2)$ \\
\hline$c / \AA ̊$ & $23.423(4)$ & $17.1521(14)$ & $9.59134(16)$ \\
\hline$\alpha /^{\circ}$ & $92.697(15)$ & $107.110(7)$ & 90 \\
\hline$\beta /^{\circ}$ & $95.671(11)$ & $93.194(5)$ & $102.3875(16)$ \\
\hline$\gamma /^{\circ}$ & $91.426(12)$ & $92.383(5)$ & 90 \\
\hline $\mathrm{V} / \AA^{3}$ & $1961.7(5)$ & $1306.76(16)$ & $2469.40(7)$ \\
\hline$Z$ & 4 & 2 & 4 \\
\hline$Z^{\prime}$ & 2 & 1 & 1 \\
\hline Wavelength/Å & 1.54184 & 1.54184 & 1.54184 \\
\hline Radiation type & $\mathrm{Cu} \mathrm{K} \alpha$ & $\mathrm{Cu} \mathrm{K} \alpha$ & $\mathrm{Cu} \mathrm{K}{ }_{\alpha}$ \\
\hline$\Theta_{\min } /^{\circ}$ & 3.798 & 4.446 & 3.898 \\
\hline$\Theta_{\max } /^{\circ}$ & 76.052 & 75.519 & 75.450 \\
\hline Measured Refl's. & 8022 & 8767 & 17410 \\
\hline Indep't Refl's & 8022 & 5199 & 5023 \\
\hline Refl's I $\geq 2 \sigma(I)$ & 4832 & 3928 & 4294 \\
\hline$R_{\mathrm{int}}$ & $\mathrm{n} / \mathrm{a}$ & 0.0324 & 0.0360 \\
\hline Parameters & 511 & 463 & 418 \\
\hline Restraints & 0 & 0 & 0 \\
\hline Largest Peak/e $\AA^{-3}$ & 0.613 & 0.349 & 0.448 \\
\hline Deepest Hole/e $\AA^{-3}$ & -0.439 & -0.271 & -0.453 \\
\hline GooF & 1.339 & 1.030 & 1.039 \\
\hline$w R_{2}$ (all data) & 0.4093 & 0.1580 & 0.1054 \\
\hline$w R_{2}$ & 0.3893 & 0.1418 & 0.0997 \\
\hline$R_{1}$ (all data) & 0.1821 & 0.0691 & 0.0462 \\
\hline$R_{1}$ & 0.1401 & 0.0528 & 0.0386 \\
\hline CCDC number & 2059154 & 2059155 & 2059156 \\
\hline
\end{tabular}


Supplementary Table S2. Hydrogen bonds observed in single crystals of the acridine model compound Acr-Hex.

\begin{tabular}{cccc}
\hline D-H $\cdots \mathbf{A}$ & $\boldsymbol{d}(\mathbf{H} \cdots \mathbf{A}) / \AA$ & $\boldsymbol{d}(\mathbf{D} \cdots \mathbf{A}) / \AA$ & $<$ (DHA) \\
\hline $\mathrm{N}(2)-\mathrm{H}(2 \mathrm{~N}) \cdots \mathrm{O}(1)$ & 1.997 & $2.830(2)$ & $178.0^{\circ}$ \\
$\mathrm{N}(3)-\mathrm{H}(3 \mathrm{~N}) \cdots \mathrm{O}(2)$ & 1.929 & $2.795(2)$ & $167.5^{\circ}$ \\
\hline
\end{tabular}

Supplementary Table S3. Hydrogen bonds observed in single crystals of the anthracene model compound Ant-Pr.

\begin{tabular}{cccc}
\hline $\mathbf{D}-\mathbf{H} \cdots \mathbf{A}$ & $\boldsymbol{d}(\mathbf{H} \cdots \mathbf{A}) / \AA$ & $\boldsymbol{d}(\mathbf{D} \cdots \mathbf{A}) / \AA$ & $<$ (DHA) \\
\hline $\mathrm{N}(1)-\mathrm{H}(1) \cdots \mathrm{O}(2)$ & 2.250 & $2.648(2)$ & $110.0^{\circ}$ \\
$\mathrm{N}(2)-\mathrm{H}(2) \cdots \mathrm{O}(3)$ & 2.282 & $2.673(2)$ & $108.1^{\circ}$ \\
$\mathrm{N}(2)-\mathrm{H}(2) \cdots \mathrm{O}(4)$ & 2.137 & $2.858(2)$ & $142.2^{\circ}$ \\
$\mathrm{N}(1)-\mathrm{H}(1) \cdots \mathrm{O}(4)$ & 2.351 & $2.961(2)$ & $131.3^{\circ}$ \\
\hline
\end{tabular}




\section{NMR Spectroscopy}

1H NMR spectrum $\left(\mathrm{CDCl}_{3}, 400 \mathrm{MHz}\right)$ of $\mathbf{1}$

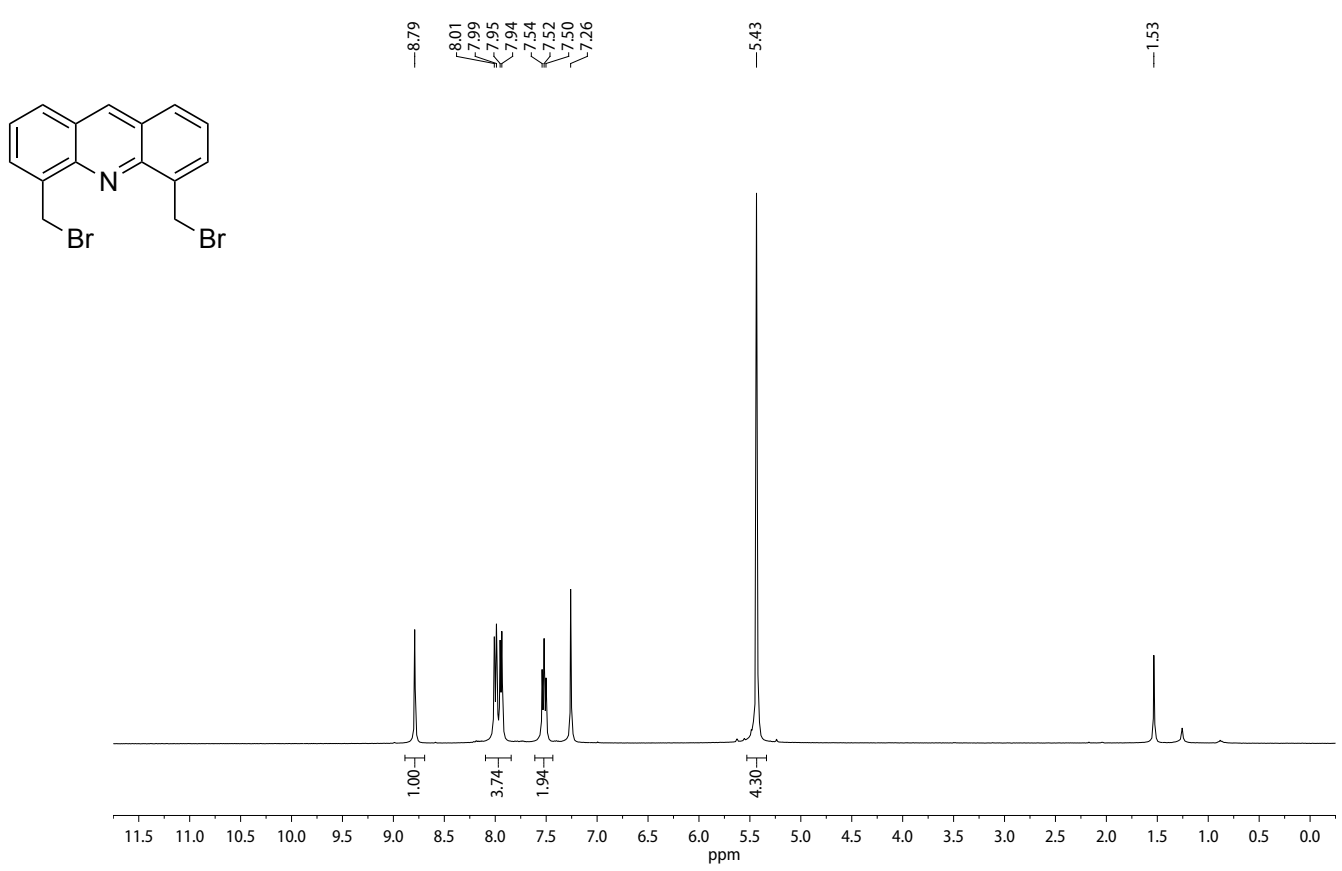

${ }^{13} \mathrm{C}$ NMR spectrum $\left(\mathrm{CDCl}_{3}, 101 \mathrm{MHz}\right)$ of $\mathbf{1}$

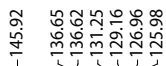

空<smiles>BrCc1cccc2cc3cccc(CBr)c3nc12</smiles>

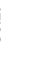
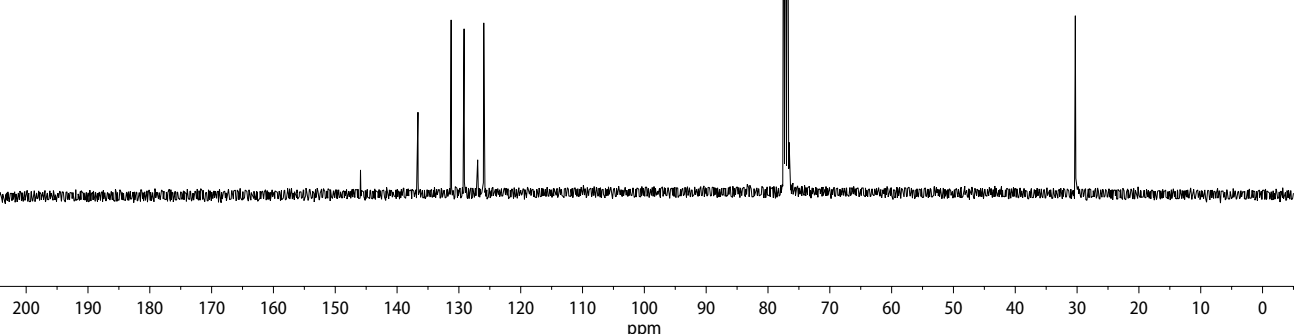
${ }^{1} \mathrm{H}$ NMR spectrum $\left(\mathrm{CDCl}_{3}, 400 \mathrm{MHz}\right)$ of 2

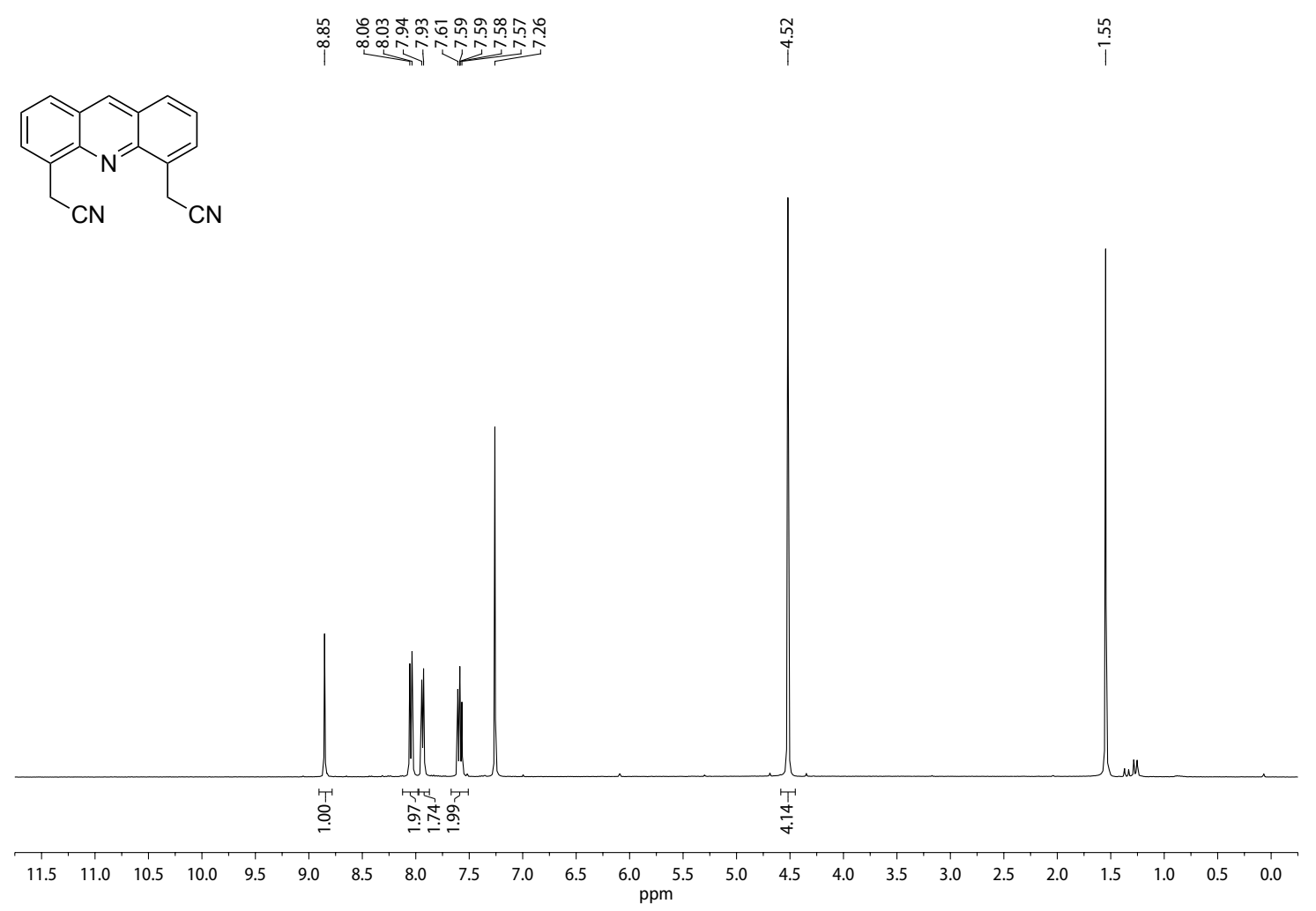

${ }^{13} \mathrm{C}$ NMR spectrum $\left(\mathrm{CDCl}_{3}, 101 \mathrm{MHz}\right)$ of 2<smiles>N#CCc1cccc2cc3cccc(CC#N)c3nc12</smiles>
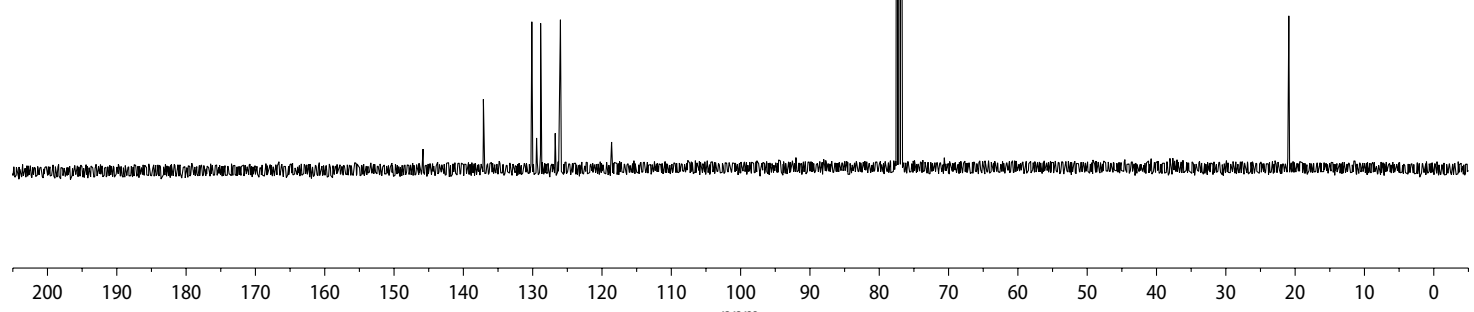
${ }^{1} \mathrm{H}$ NMR spectrum (DMSO- $d_{6}, 400 \mathrm{MHz}$ ) of $\mathbf{3} \cdot \mathbf{x H C l}$
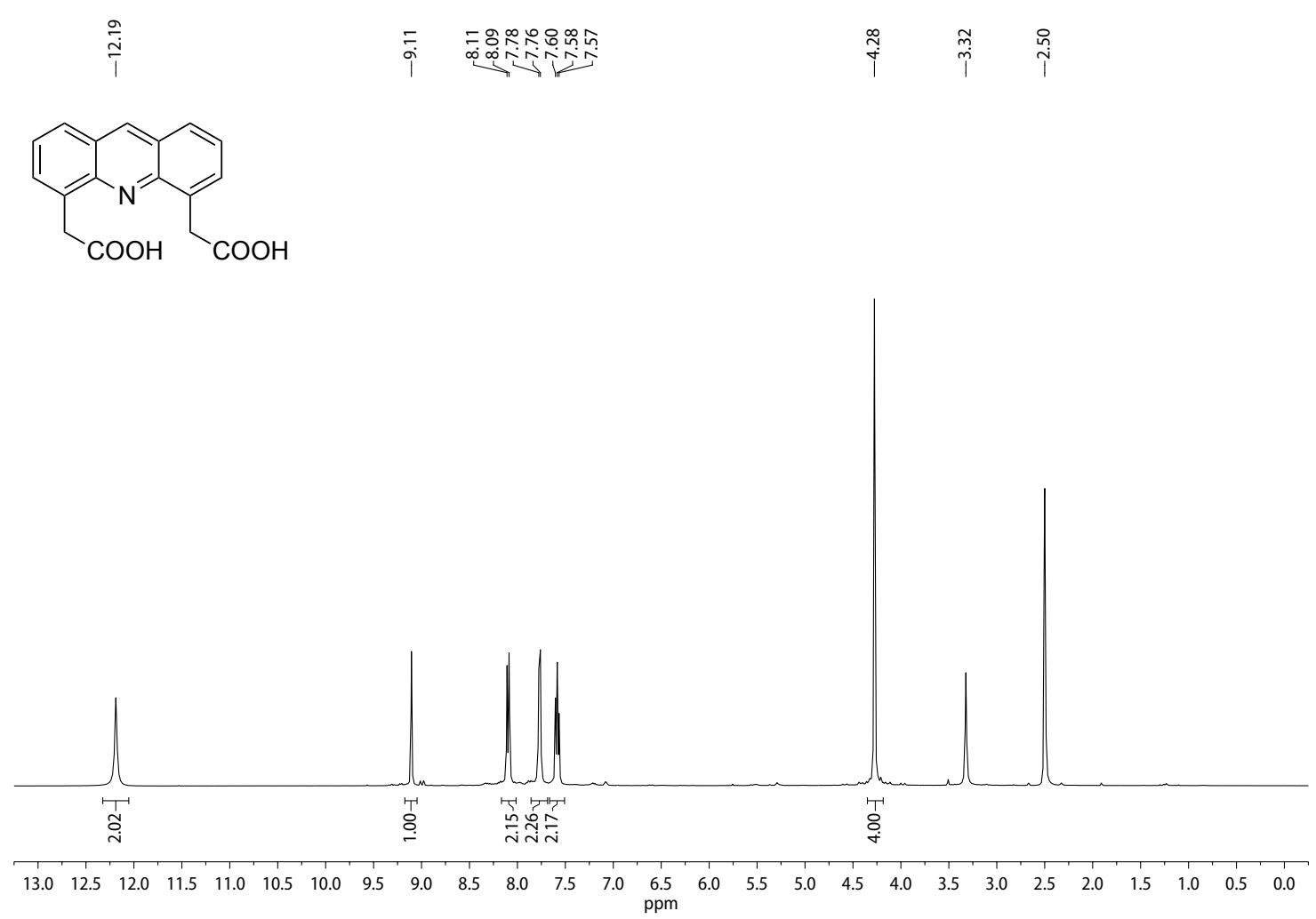

${ }^{13} \mathrm{C}$ NMR spectrum (DMSO- $d_{6}, 101 \mathrm{MHz}$ ) of $\mathbf{3} \cdot \mathbf{x H C l}$
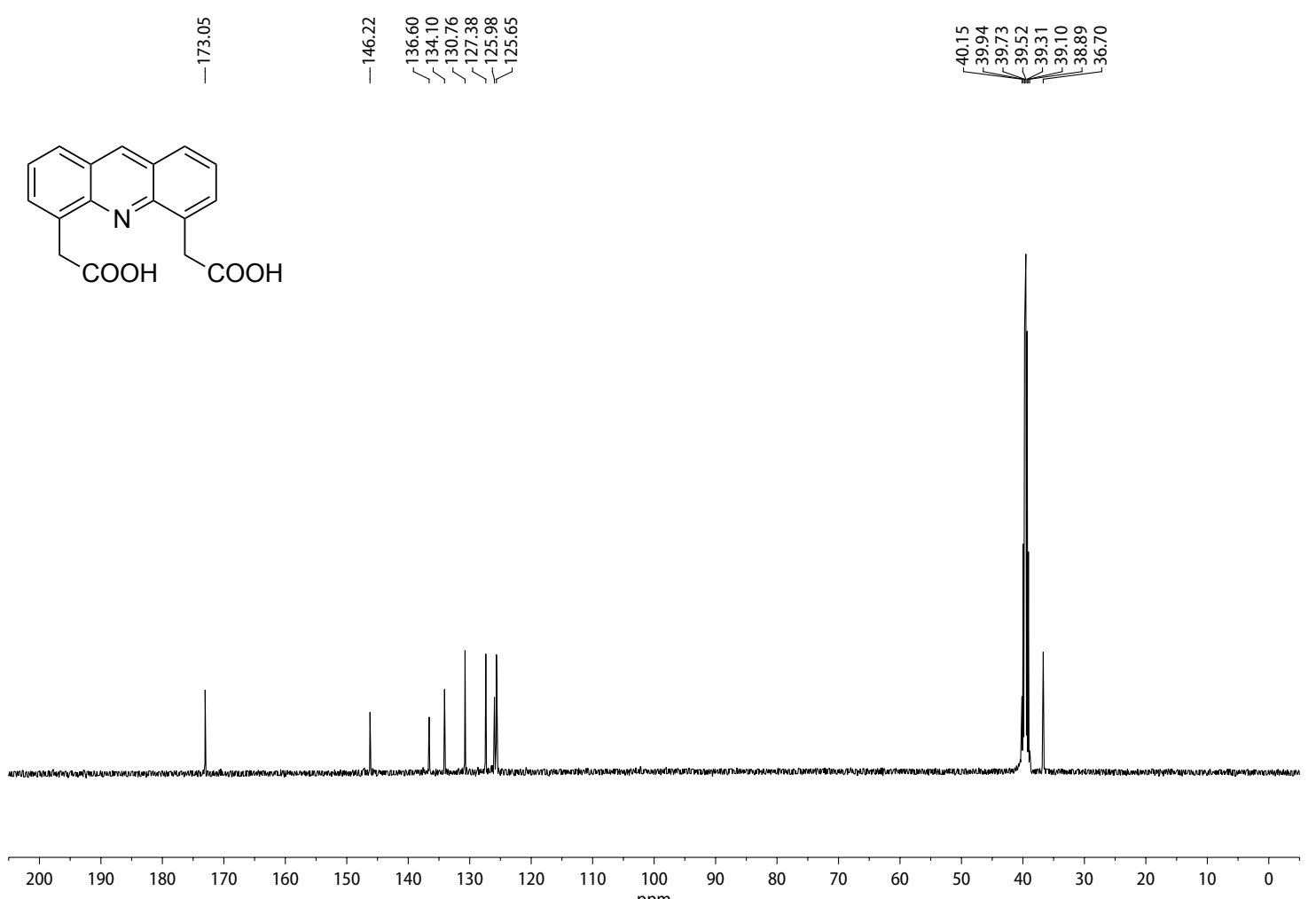
${ }^{1} \mathrm{H}$ NMR spectrum $\left(\mathrm{CDCl}_{3}, 400 \mathrm{MHz}\right)$ of 4

割

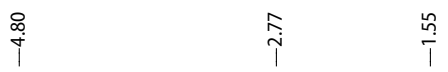<smiles>O=C(Cc1cccc2cc3ccccc3nc12)ON1C(=O)CCC1=O</smiles>

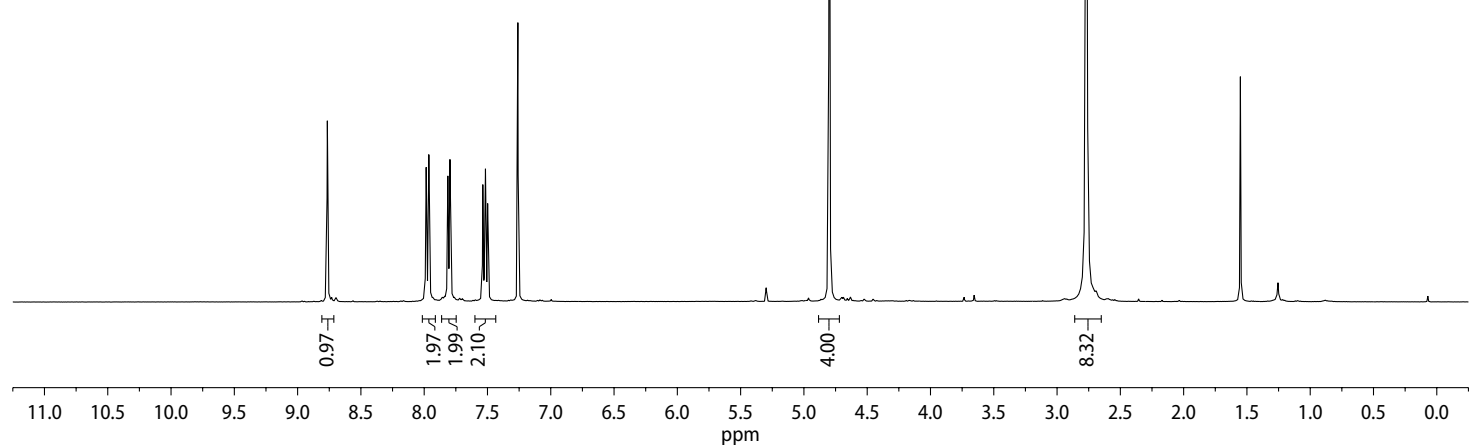

${ }^{1} \mathrm{H}$ NMR spectrum $\left(\mathrm{CDCl}_{3}, 400 \mathrm{MHz}\right)$ of 4

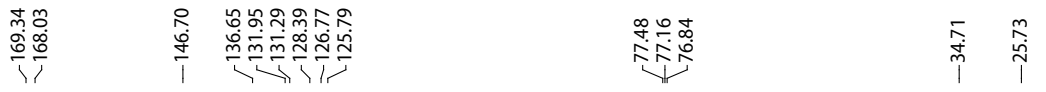<smiles>Cc1cccc2cccc(CC(=O)OC(=O)Cc3cccc4ccccc34)c12</smiles>
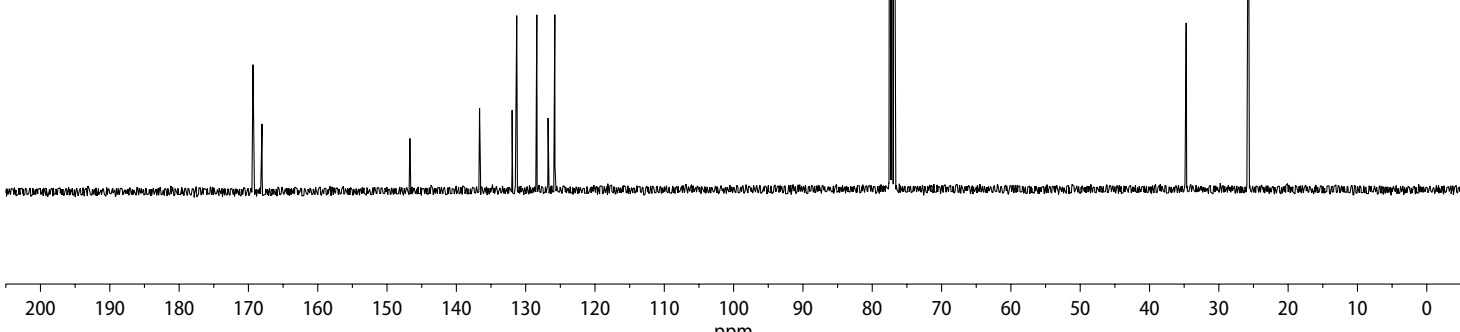
${ }^{1} \mathrm{H}$ NMR spectrum (DMSO- $d_{6}, 400 \mathrm{MHz}$ ) of Acr-Pr

象<smiles>CCCNC(=O)Cc1cccc2cccc(CC(=O)NCCC)c12</smiles>

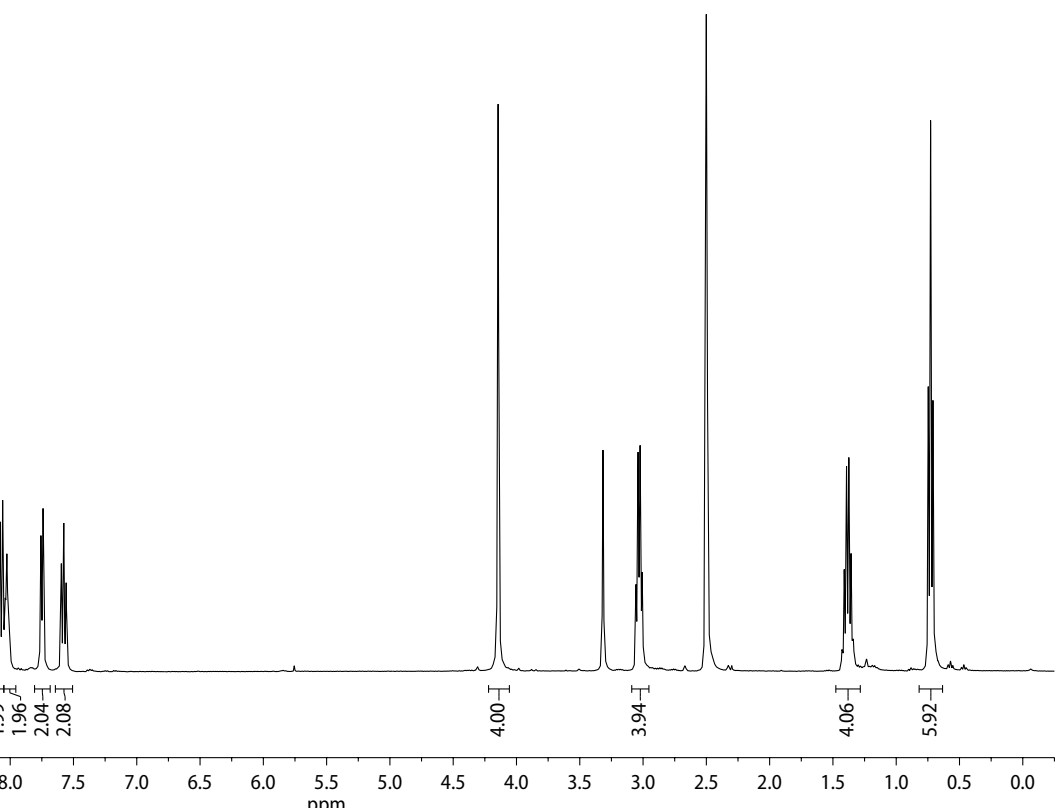

${ }^{13} \mathrm{C}$ NMR spectrum (DMSO- $d_{6}, 101 \mathrm{MHz}$ ) of Acr-Pr

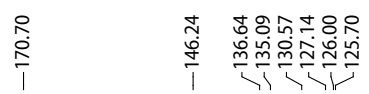

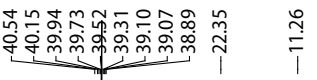<smiles>CCCNC(=O)Cc1cccc2cc3cccc(CC(=O)NCCC)c3nc12</smiles>
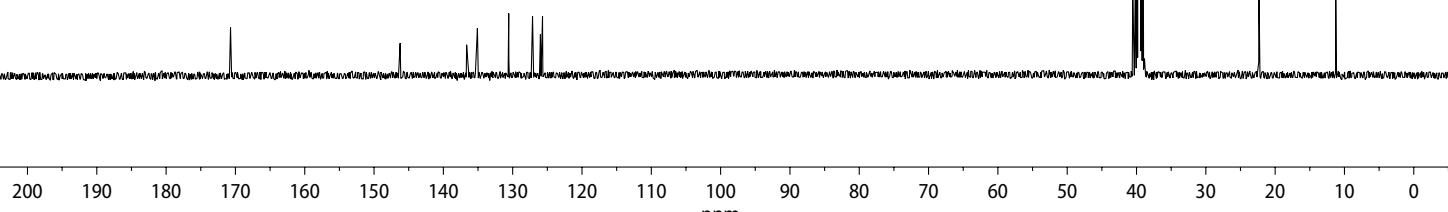
${ }^{1} \mathrm{H}$ NMR spectrum (DMSO- $d_{6}, 400 \mathrm{MHz}$ ) of Acr-Hex

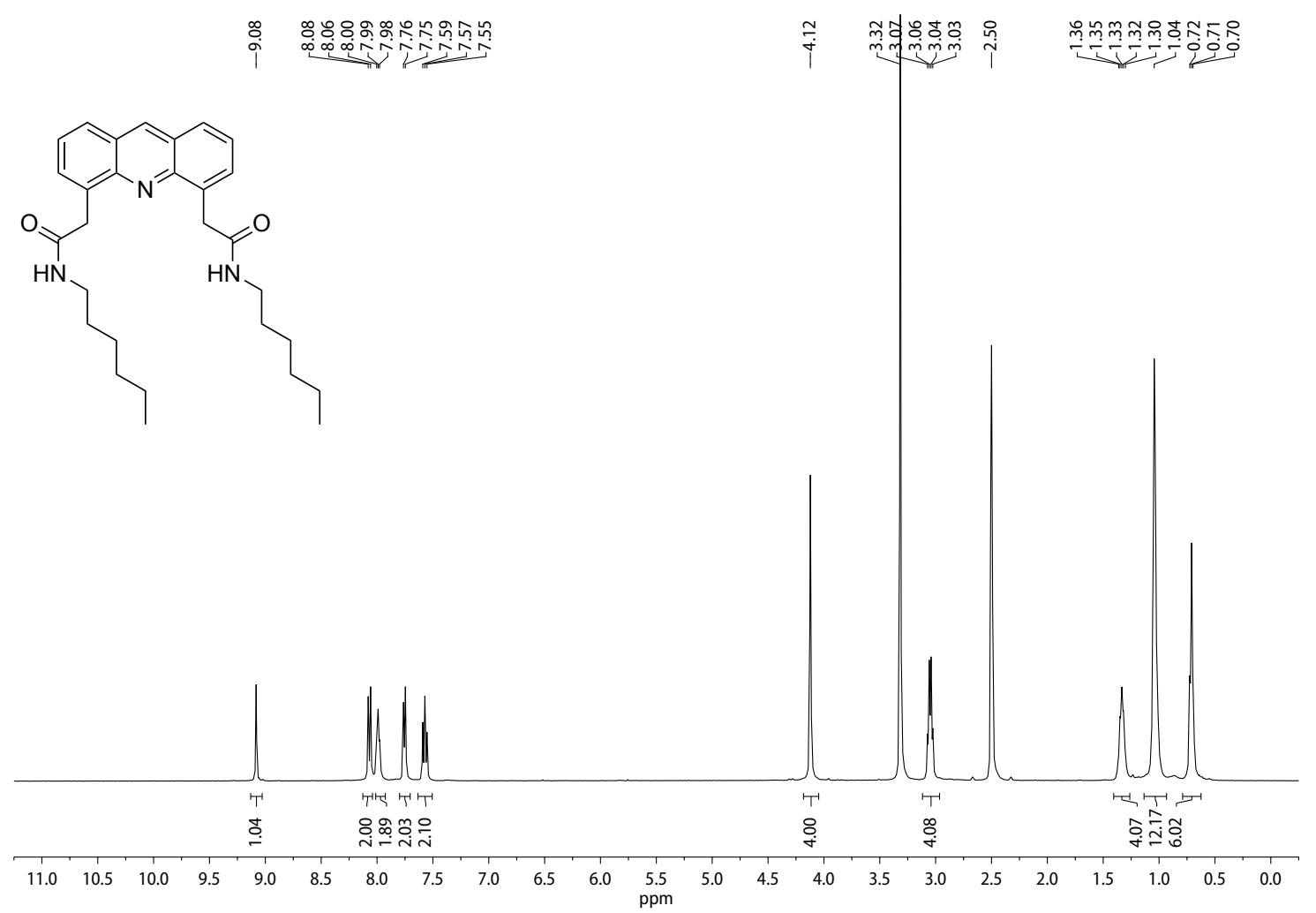

${ }^{13} \mathrm{C}$ NMR spectrum (DMSO- $d_{6}, 101 \mathrm{MHz}$ ) of Acr-Hex
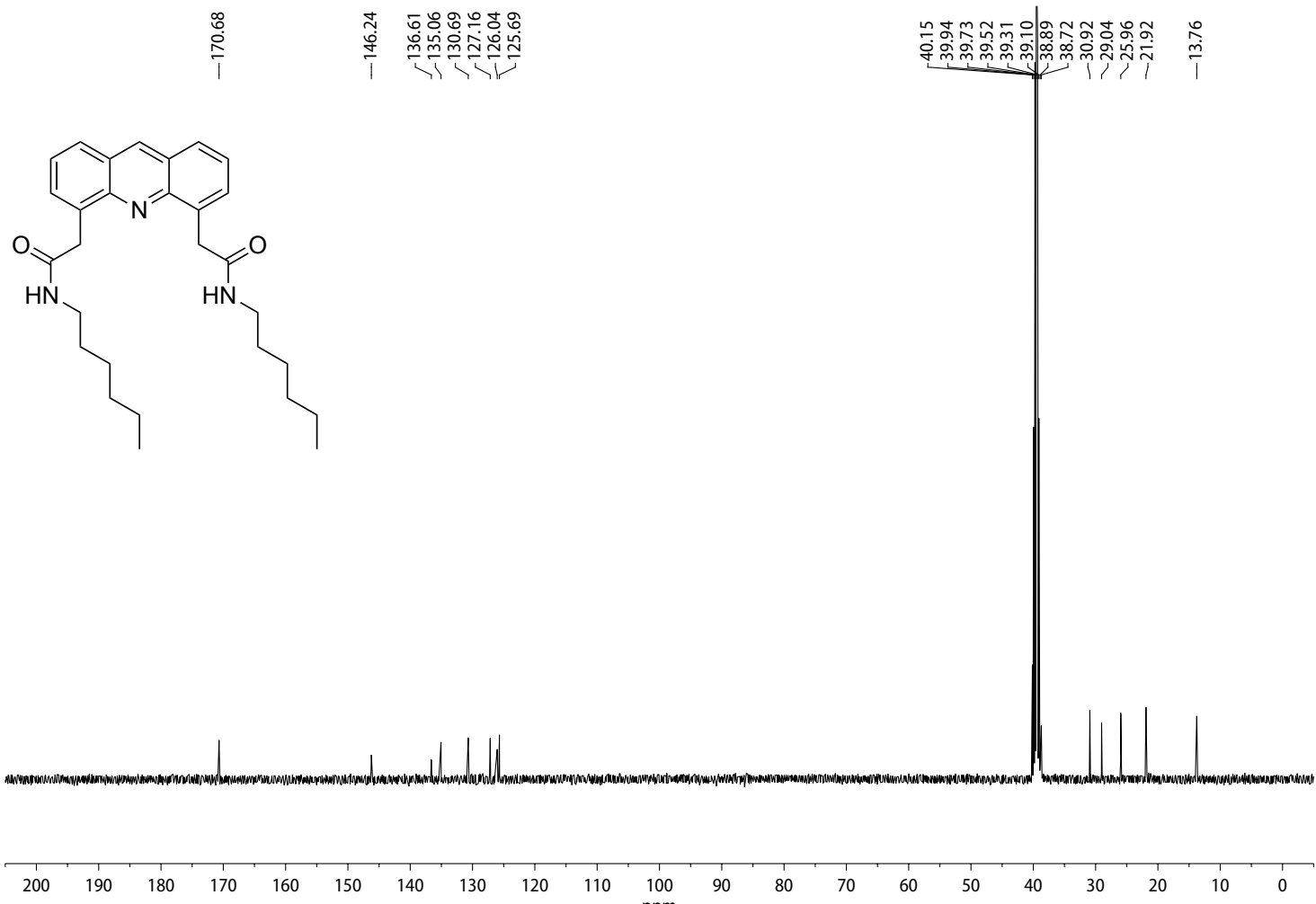
${ }^{1} \mathrm{H}$ NMR spectrum $\left(\mathrm{CD}_{2} \mathrm{Cl}_{2}, 400 \mathrm{MHz}\right)$ of $\mathbf{5}$

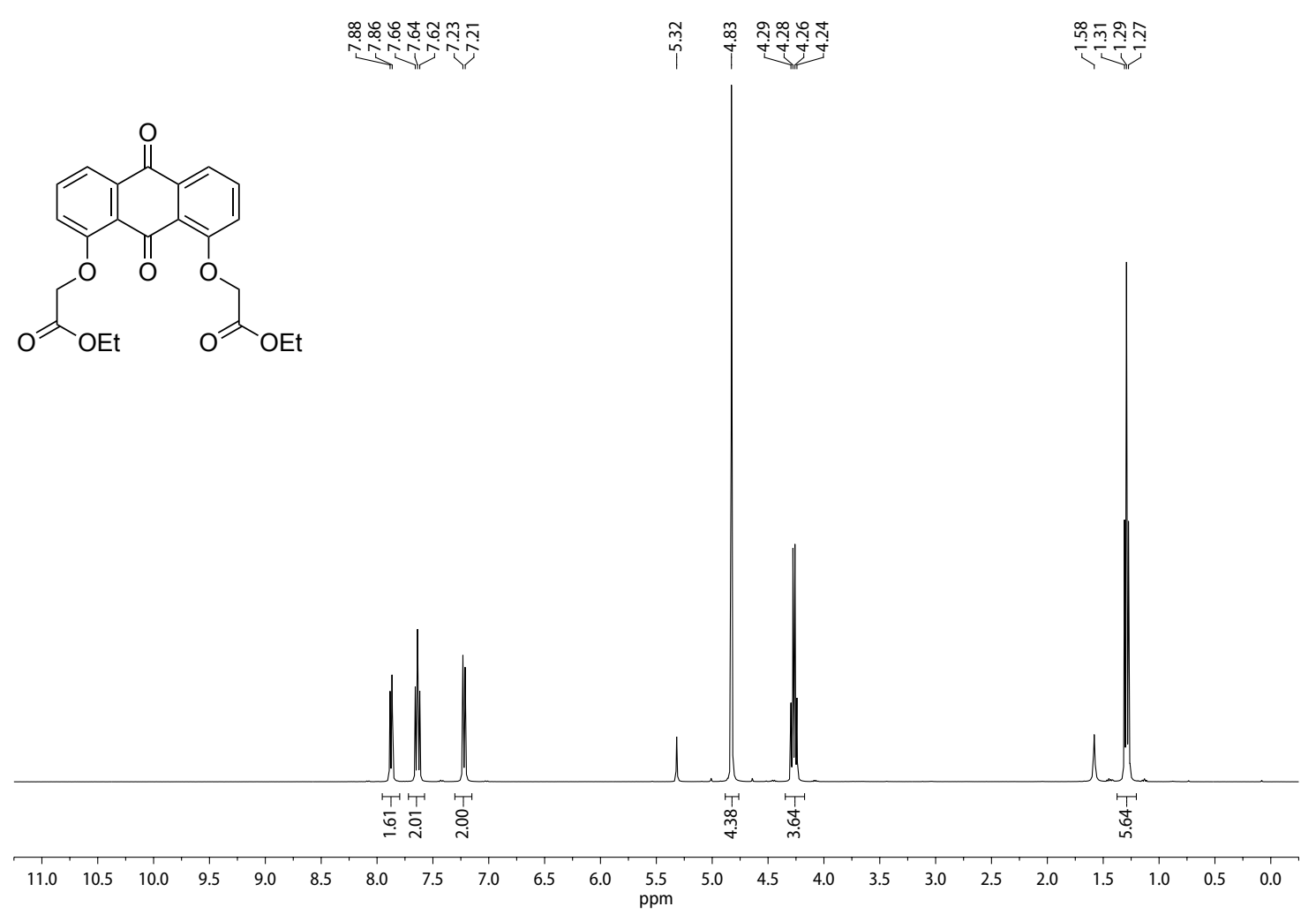

${ }^{13} \mathrm{C}$ NMR spectrum $\left(\mathrm{CD}_{2} \mathrm{Cl}_{2}, 151 \mathrm{MHz}\right)$ of 5

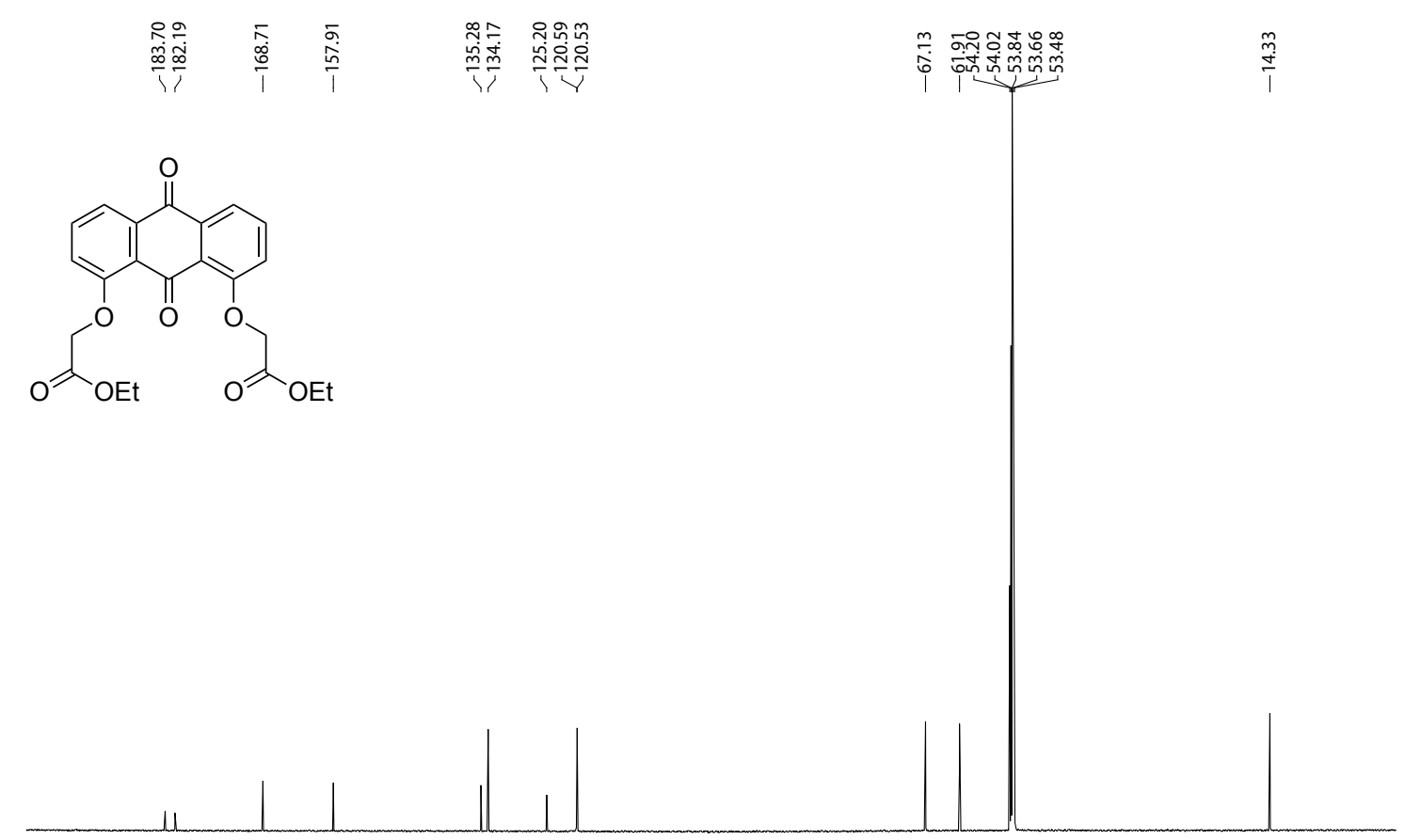

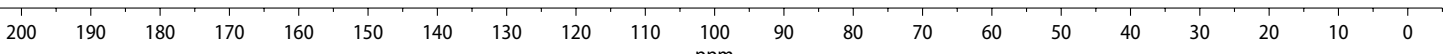


${ }^{1} \mathrm{H}$ NMR spectrum (DMSO- $d_{6}, 400 \mathrm{MHz}$ ) of 6

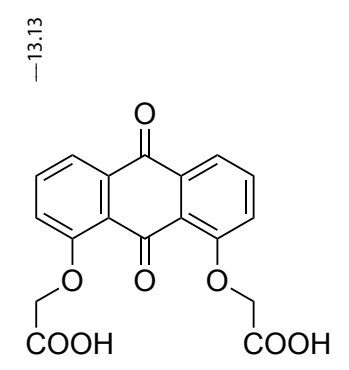

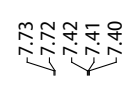

$\overline{\frac{9}{1}}$

$\bar{m}$
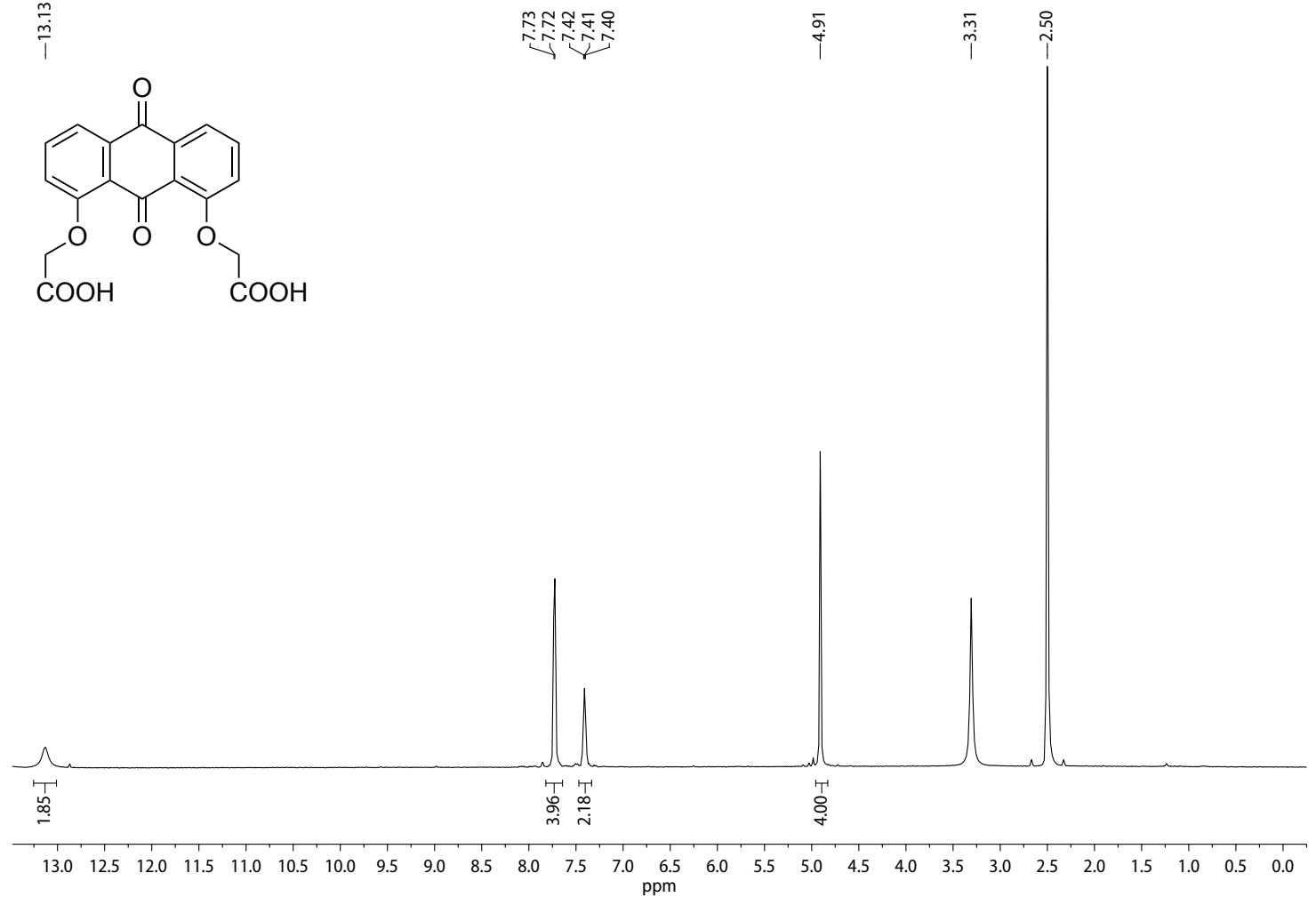

${ }^{13} \mathrm{C}$ NMR spectrum (DMSO- $d_{6}, 101 \mathrm{MHz}$ ) of 6

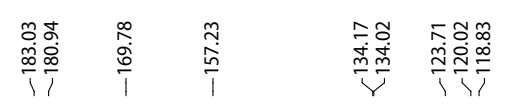

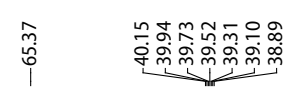
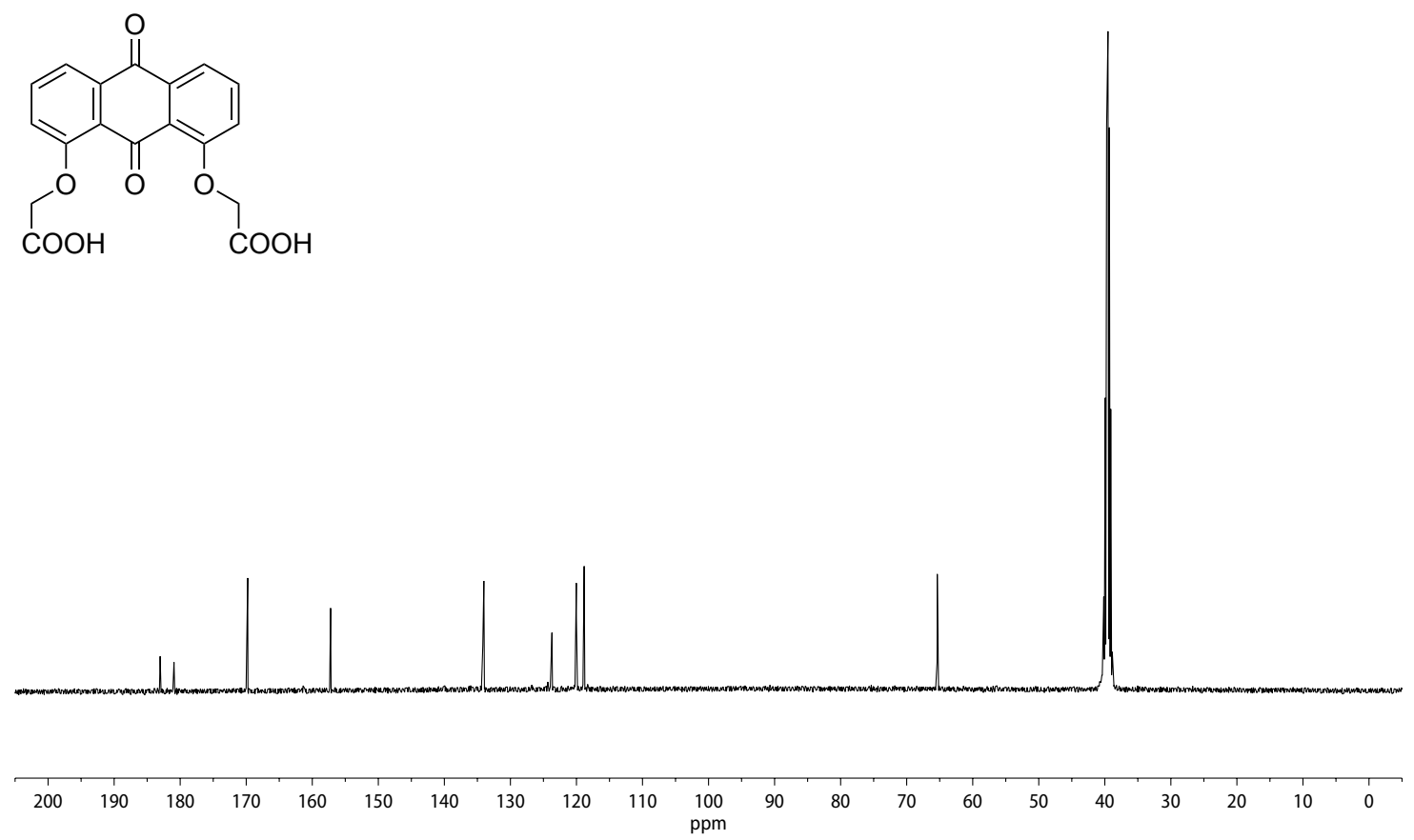
${ }^{1} \mathrm{H}$ NMR spectrum (DMSO- $d_{6}, 400 \mathrm{MHz}$ ) of 7

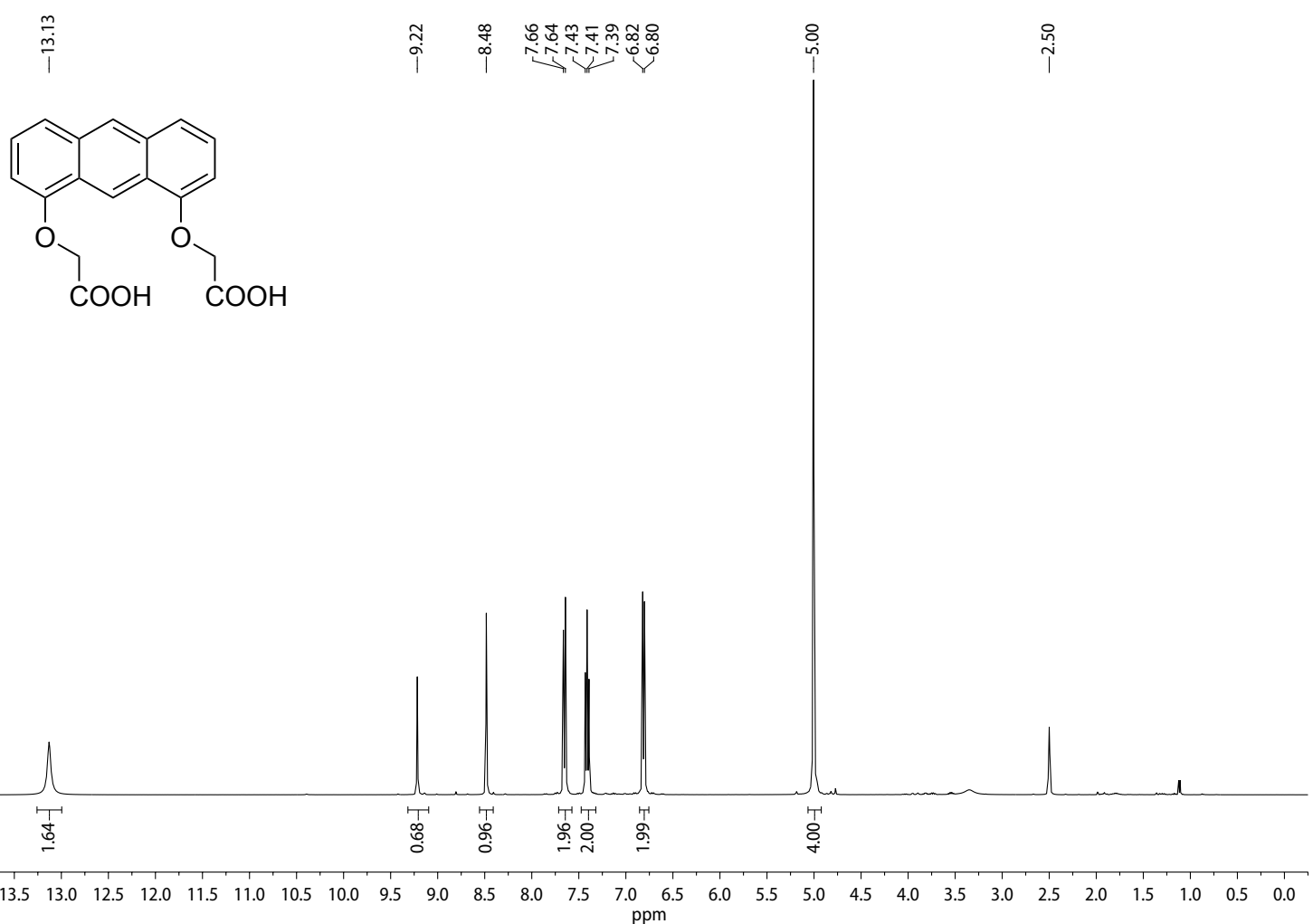

${ }^{13} \mathrm{C}$ NMR spectrum (DMSO- $d_{6}, 101 \mathrm{MHz}$ ) of 7

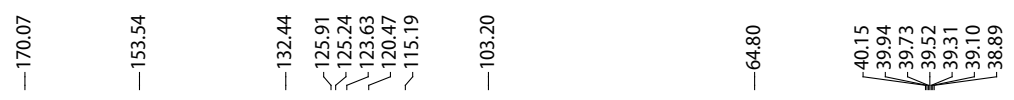<smiles>O=C(O)COc1cccc2cc3cccc(OCC(=O)O)c3cc12</smiles>
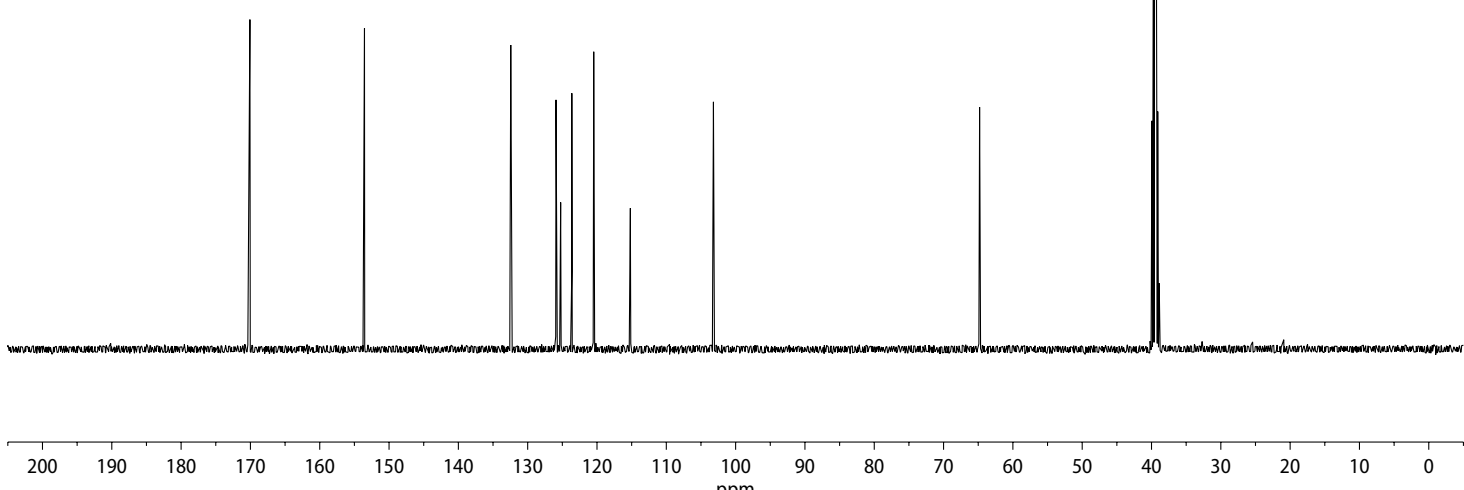
${ }^{1} \mathrm{H}$ NMR spectrum $\left(\mathrm{CDCl}_{3}, 400 \mathrm{MHz}\right)$ of Ant-Pr

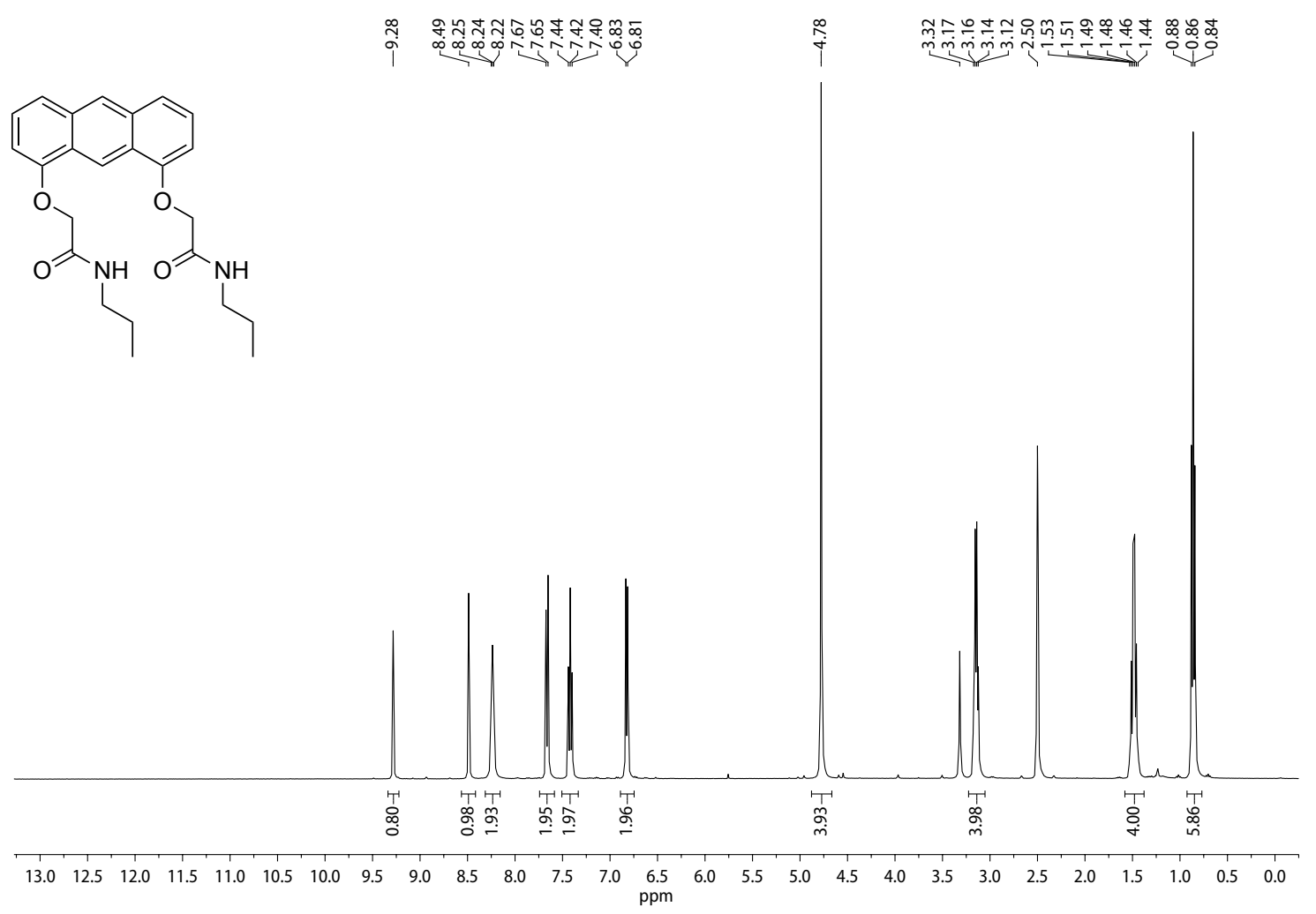

${ }^{13} \mathrm{C}$ NMR spectrum (DMSO- $d_{6}, 101 \mathrm{MHz}$ ) of Ant-Pr
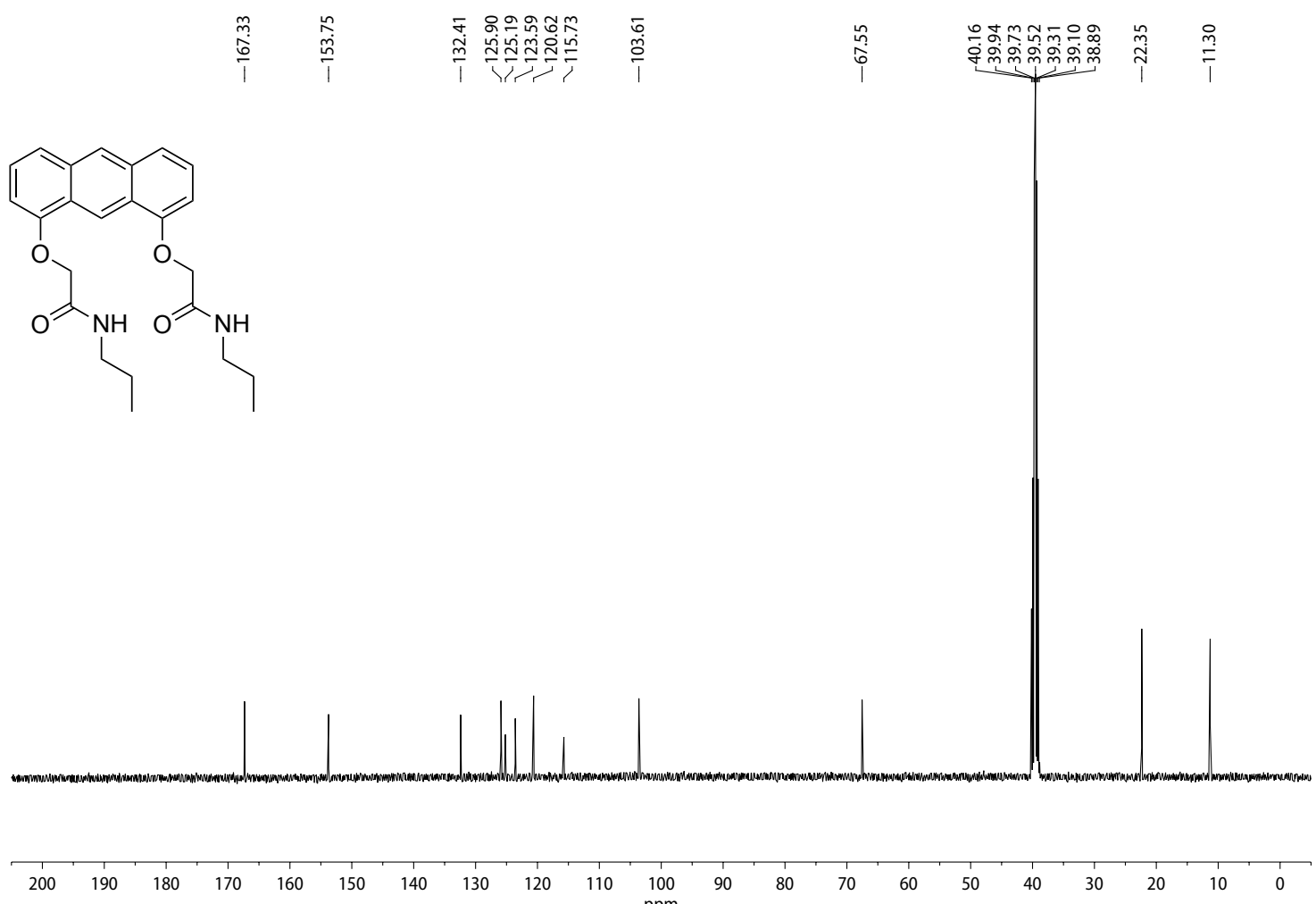
${ }^{1} \mathrm{H}$ NMR spectrum (CDCl $3:$ HFIP- $\left.d_{2} 90: 10,400 \mathrm{MHz}\right)$ of PA6Ac

罂

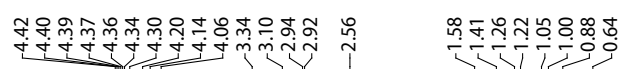

$\overbrace{0}^{(}$

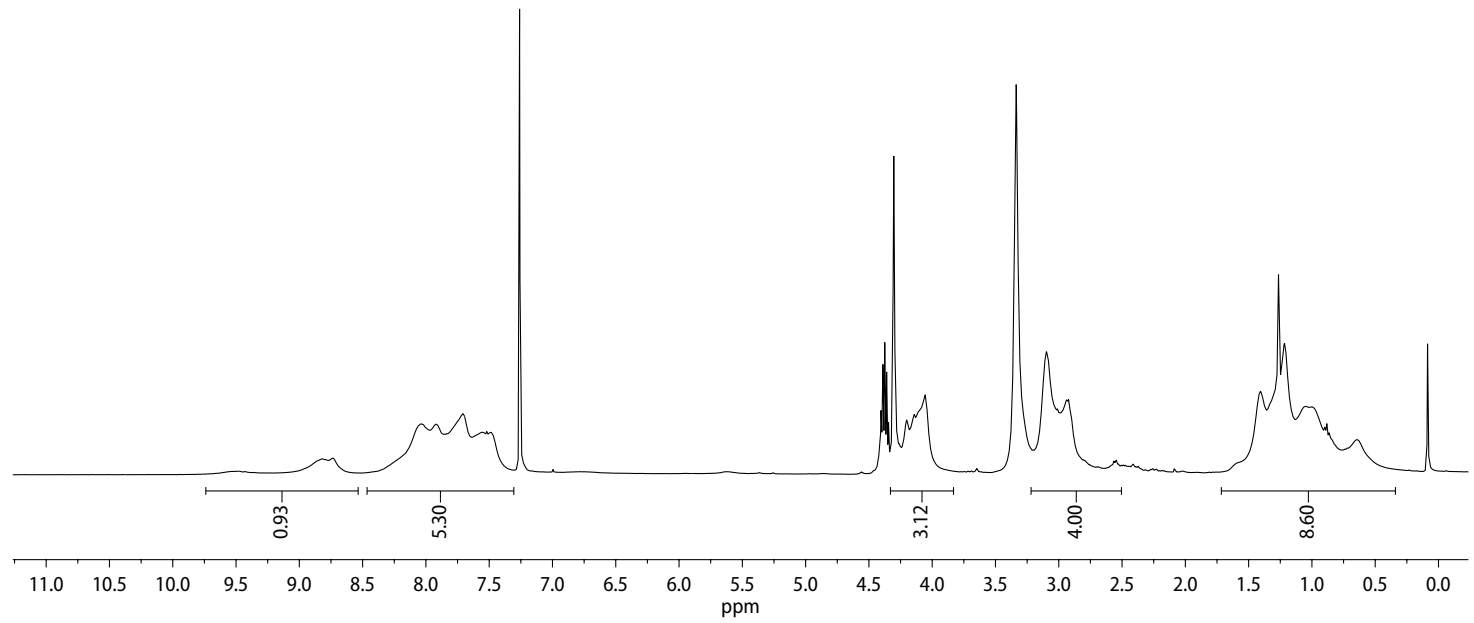

${ }^{1} \mathrm{H}$ NMR spectrum $\left(\mathrm{CDCl}_{3}: \mathrm{HFIP}-d_{2}\right.$ 90:10, $\left.400 \mathrm{MHz}\right)$ of PA8Ac

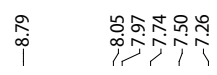

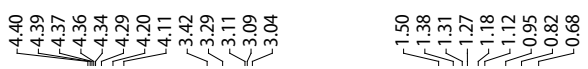

$\overbrace{0}^{(}$

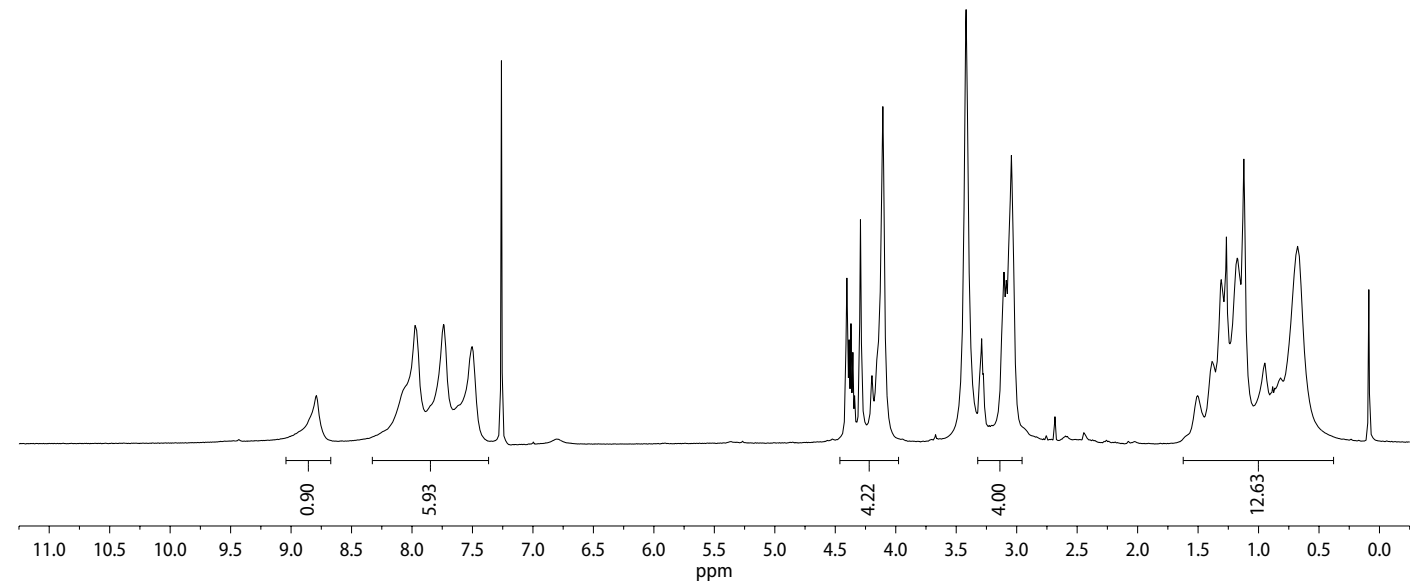


${ }^{1} \mathrm{H}$ NMR spectrum $\left(\mathrm{CDCl}_{3}: \mathrm{HFIP}-d_{2}\right.$ 90:10, $400 \mathrm{MHz}$ ) of PA10Ac

$$
\text { i }
$$
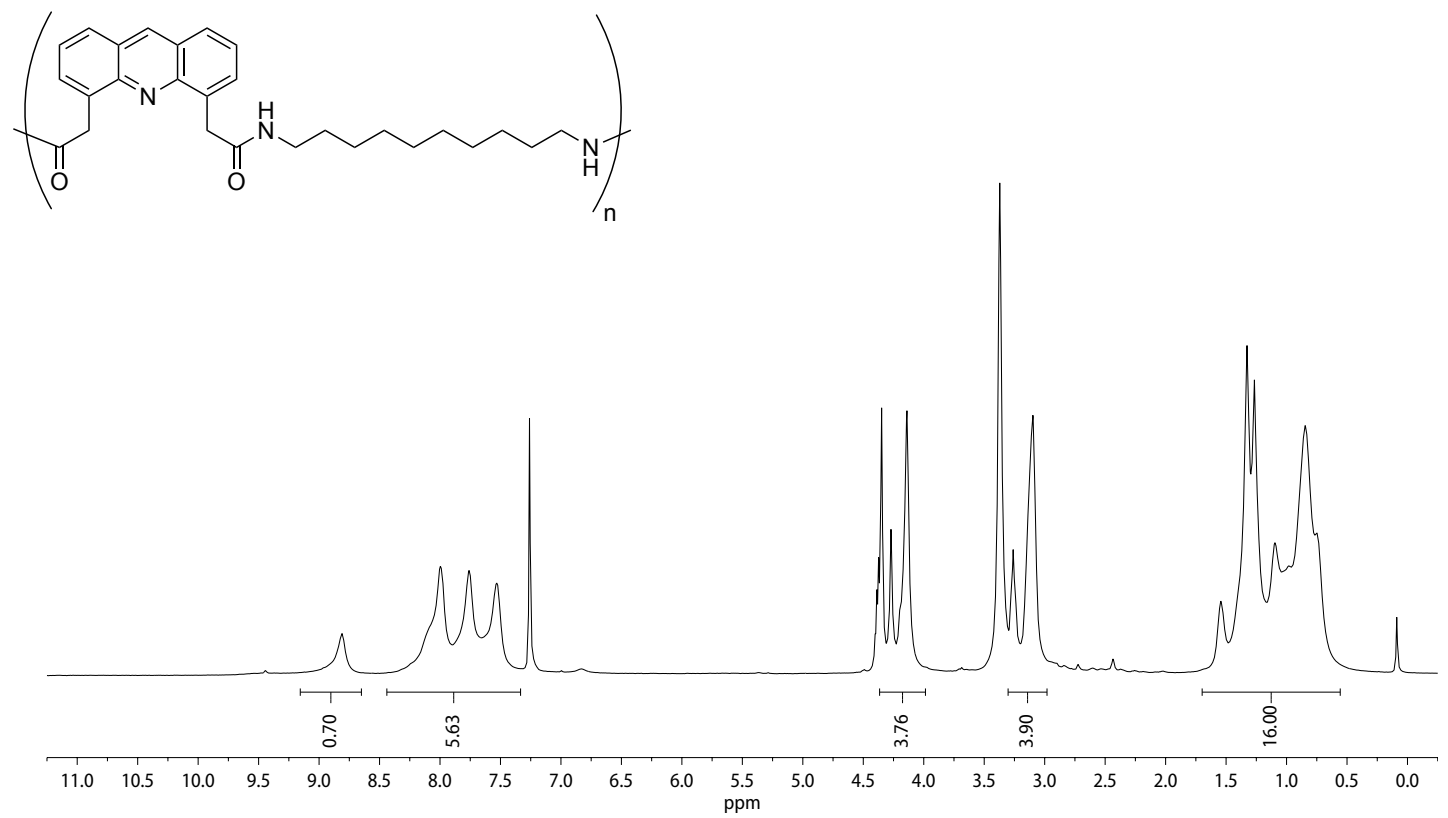

1H NMR spectrum $\left(\mathrm{CDCl}_{3}: \mathrm{HFIP}-d_{2}\right.$ 90:10, $\left.400 \mathrm{MHz}\right)$ of PA12Ac

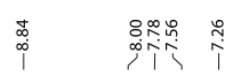

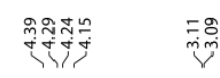
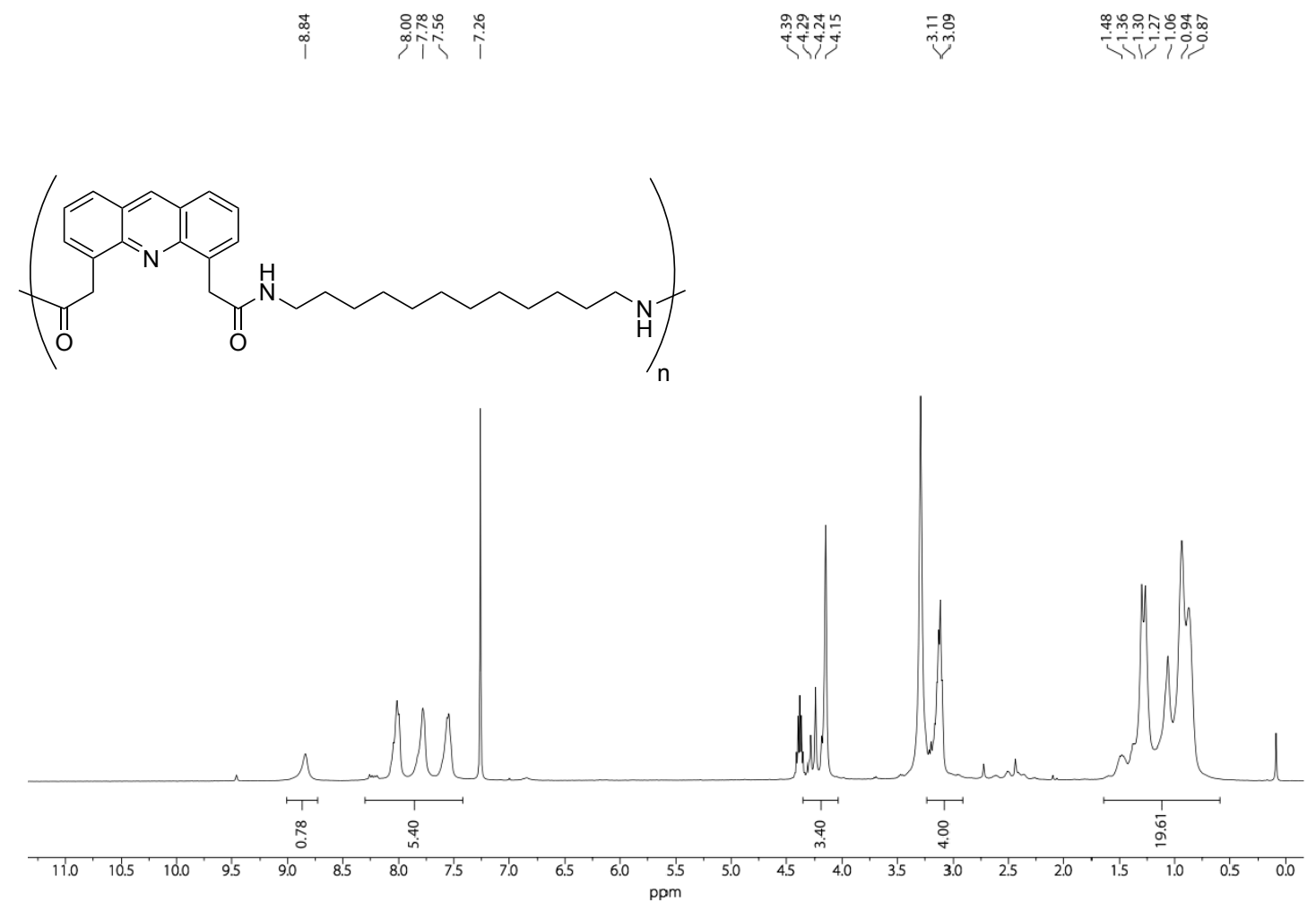
${ }^{1} \mathrm{H}$ NMR spectrum $\left(\mathrm{CDCl}_{3}: \mathrm{HFIP}-d_{2}\right.$ 90:10, $400 \mathrm{MHz}$ ) of PA6Ant

蛋

$\underbrace{0}_{0}$

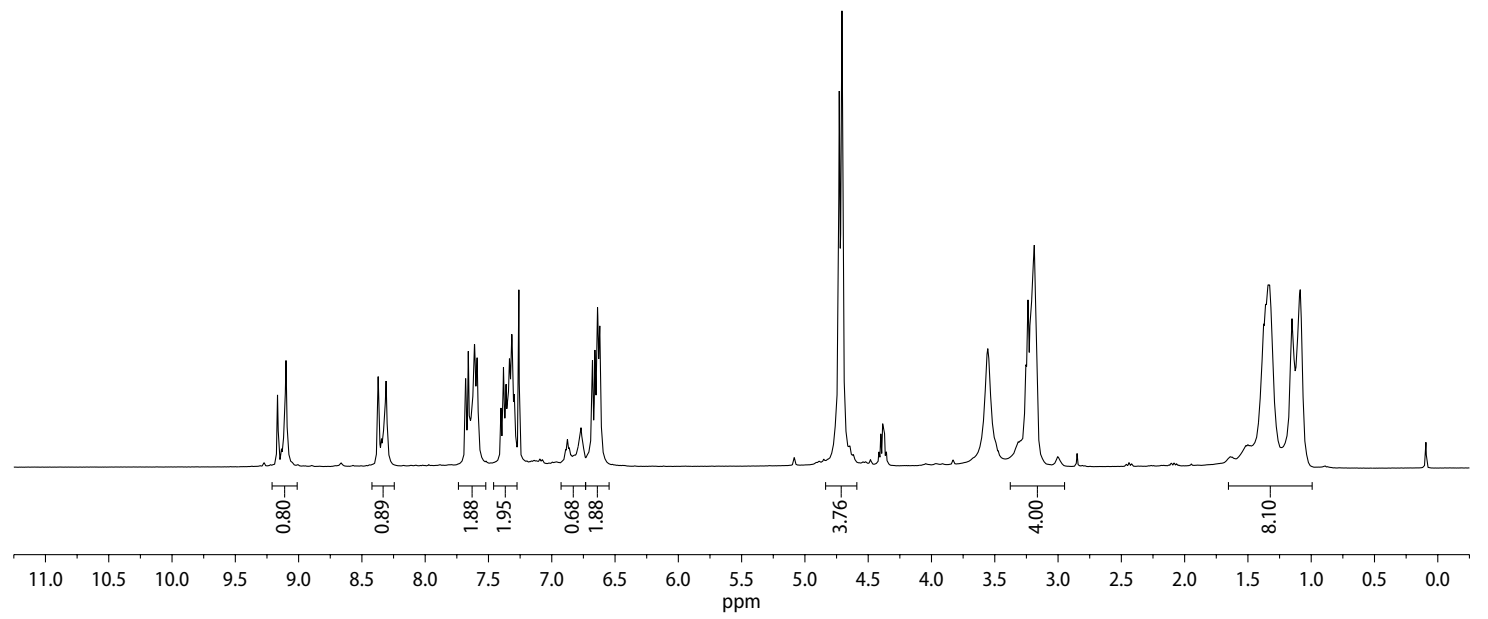

${ }^{1} \mathrm{H}$ NMR spectrum $\left(\mathrm{CDCl}_{3}: \mathrm{HFIP}-d_{2} 90: 10,400 \mathrm{MHz}\right.$ ) of PA8Ant
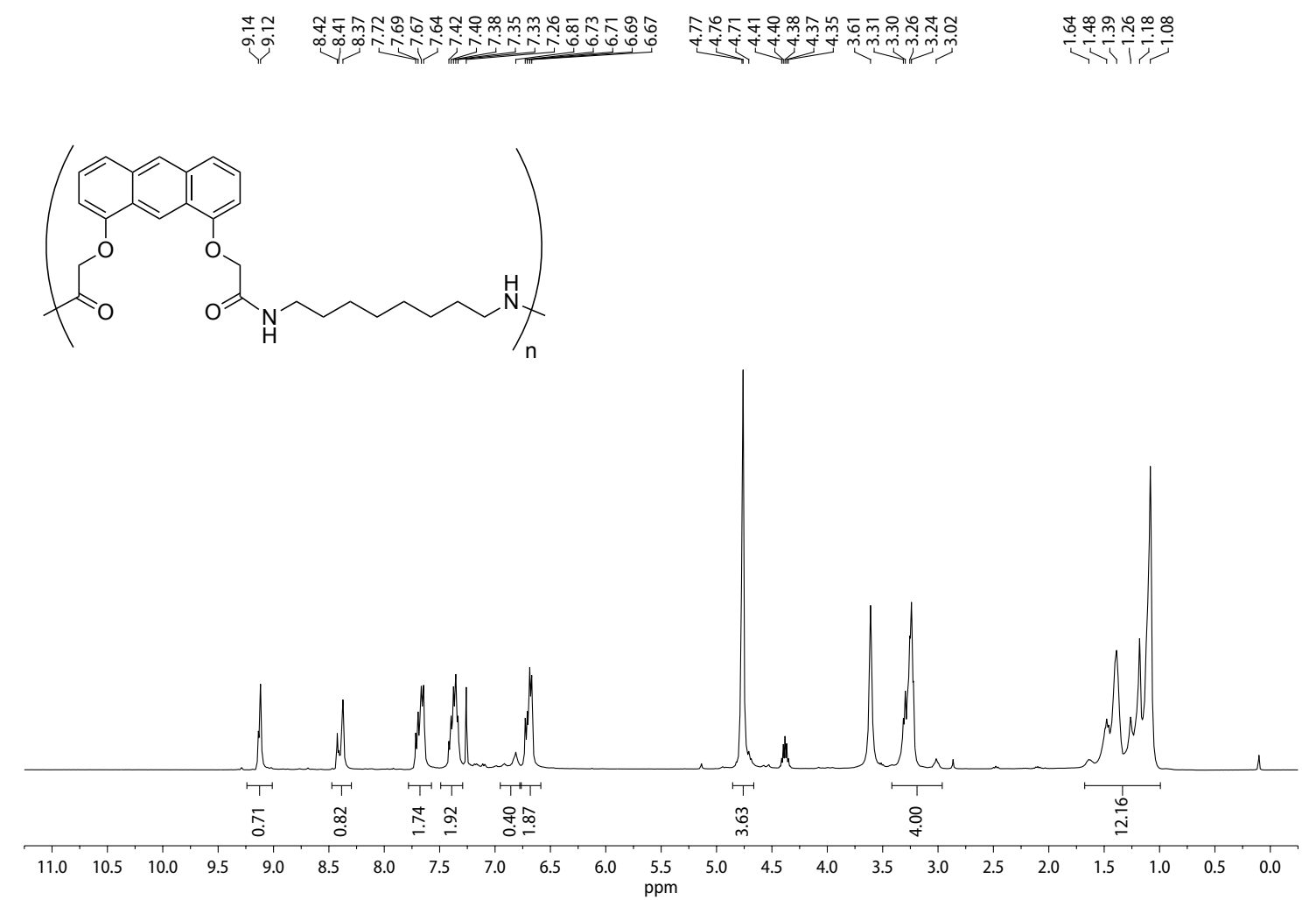
${ }^{1} \mathrm{H}$ NMR spectrum $\left(\mathrm{CDCl}_{3}:\right.$ HFIP- $d_{2}$ 90:10, $\left.400 \mathrm{MHz}\right)$ of PA10Ant

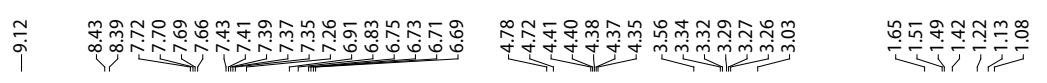<smiles>CC(C)(C)NCCCCCCCCCCNC(=O)COc1cccc2cc3cccc(OCC(=O)C(C)(C)C)c3cc12</smiles>

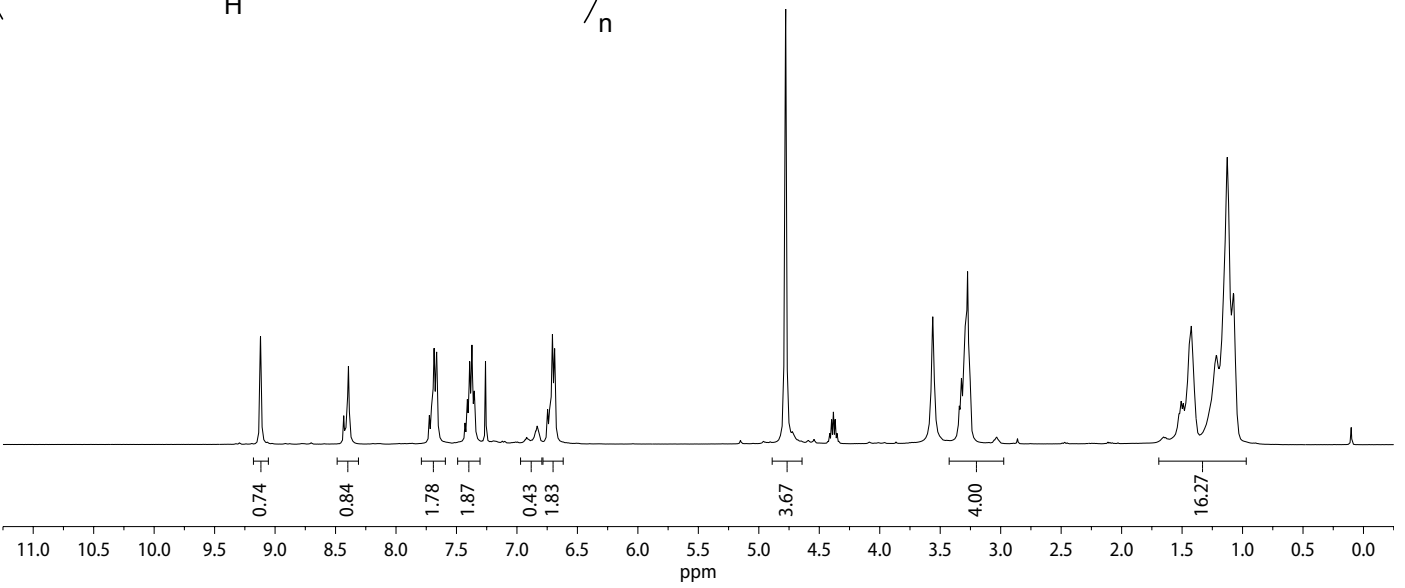

${ }^{1} \mathrm{H}$ NMR spectrum $\left(\mathrm{CDCl}_{3}: \mathrm{HFIP}-d_{2}\right.$ 90:10, $\left.400 \mathrm{MHz}\right)$ of PA12Ant

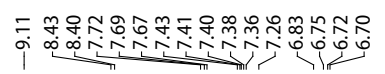

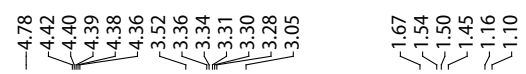
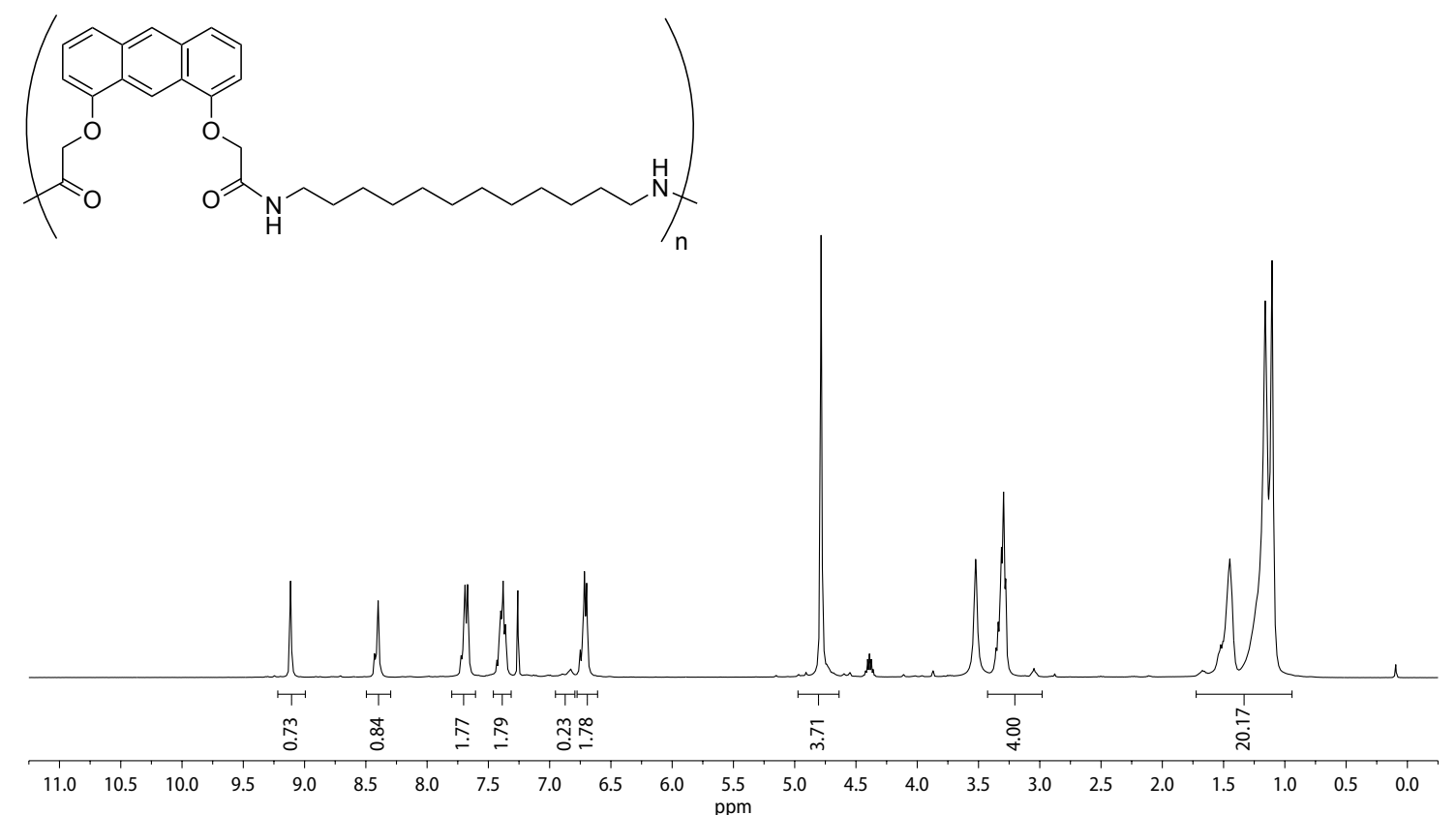


\section{References}

(1) Mayo, S. L.; Olafson, B. D.; Goddard, W. A. DREIDING: A Generic Force Field for Molecular Simulations. J. Phys. Chem. 1990, 94 (26), 8897-8909.

(2) CrysAlis PRO; Rigaku Oxford Diffraction, 2015.

(3) Sheldrick, G. M. A Short History of SHELX. Acta Crystallogr. A 2008, 64 (1), 112-122.

(4) Sheldrick, G. M. SHELXT - Integrated Space-Group and Crystal-Structure Determination. Acta Crystallogr. Sect. Found. Adv. 2015, 71 (1), 3-8.

(5) Sheldrick, G. M. Crystal Structure Refinement with SHELXL. Acta Crystallogr. Sect. C Struct. Chem. 2015, 71 (1), 3-8.

(6) Chai, J.-D.; Head-Gordon, M. Long-Range Corrected Hybrid Density Functionals with Damped Atom-Atom Dispersion Corrections. Phys. Chem. Chem. Phys. 2008, 10 (44), 6615-6620.

(7) Weigend, F.; Ahlrichs, R. Balanced Basis Sets of Split Valence, Triple Zeta Valence and Quadruple Zeta Valence Quality for H to Rn: Design and Assessment of Accuracy. Phys. Chem. Chem. Phys. 2005, 7 (18), 3297-3305.

(8) Marenich, A. V.; Cramer, C. J.; Truhlar, D. G. Universal Solvation Model Based on Solute Electron Density and on a Continuum Model of the Solvent Defined by the Bulk Dielectric Constant and Atomic Surface Tensions. J. Phys. Chem. $B$ 2009, 113 (18), 6378-6396.

(9) Chiron, J.; Galy, J.-P. Reactivity of the Acridine Ring: One-Pot Regioselective Single and Double Bromomethylation of Acridine and Some Derivatives. Synlett 2003, No. 15, 2349-2350.

(10) Ghosh, K.; Kar, D. Anthraquinone Coupled Benzothiazole-Based Receptor for Selective Sensing of Cu2+. J. Incl. Phenom. Macrocycl. Chem. 2012, 77 (1), 67-74.

(11) Park, D. H.; Kang, S.; Lee, H.-J.; Nam, K.; Jeon, S. Synthesis and Electrochemistry of Diester-Anthraquinone as Lithium-Ion Selective Receptor. Bull. Korean Chem. Soc. 2001, 22, 638-640.

(12) Sharghi, H.; Khoshnood, A.; Doroodmand, M. M.; Khalifeh, R. Rapid, Eco-Friendly, and One-Pot Synthesis of New Lariat Ethers Based on Anthraquinone by Using ZnO Nanoparticles via "Mannich" Reaction under Solvent-Free Condition. J. Heterocycl. Chem. 2015, 53 (1), 164-174.

(13) Kasama, K.; Kikuchi, K.; Nishida, Y.; Kokubun, H. Deactivation Mechanism of Excited Acridine and 9-Substituted Acridines in Water. J. Phys. Chem. 1981, 85 (26), 4148-4153.

(14) Kellmann, A. Intersystem Crossing and Internal Conversion Quantum Yields of Acridine in Polar and Nonpolar Solvents. J. Phys. Chem. 1977, 81 (12), 1195-1198.

(15) Ryan, E. T.; Xiang, T.; Johnston, K. P.; Fox, M. A. Absorption and Fluorescence Studies of Acridine in Subcritical and Supercritical Water. J. Phys. Chem. A 1997, 101 (10), 1827-1835.

(16) Negrón-Encarnación, I.; Arce, R.; Jiménez, M. Characterization of Acridine Species Adsorbed on (NH4)2SO4, SiO2, Al203, and MgO by Steady-State and Time-Resolved Fluorescence and Diffuse Reflectance Techniques. J. Phys. Chem. A 2005, 109 (5), 787-797.

(17) Becker, H. Dieter. Unimolecular Photochemistry of Anthracenes. Chem. Rev. 1993, 93 (1), 145-172.

(18) Bouas-Laurent, H.; Castellan, A.; Desvergne, J.-P.; Lapouyade, R. Photodimerization of Anthracenes in Fluid Solution: Structural Aspects. Chem. Soc. Rev. 2000, 29 (1), 43-55.

(19) Bouas-Laurent, H.; Castellan, A.; Desvergne, J.-P.; Lapouyade, R. Photodimerization of Anthracenes in Fluid Solutions: (Part 2) Mechanistic Aspects of the Photocycloaddition and of the Photochemical and Thermal Cleavage. Chem. Soc. Rev. 2001, 30 (4), 248-263.

(20) Lamm, J.-H.; Glatthor, J.; Weddeling, J.-H.; Mix, A.; Chmiel, J.; Neumann, B.; Stammler, H.-G.; Mitzel, N. W. Polyalkynylanthracenes - Syntheses, Structures and Their Behaviour towards UV Irradiation. Org. Biomol. Chem. 2014, 12 (37), 7355-7365. 